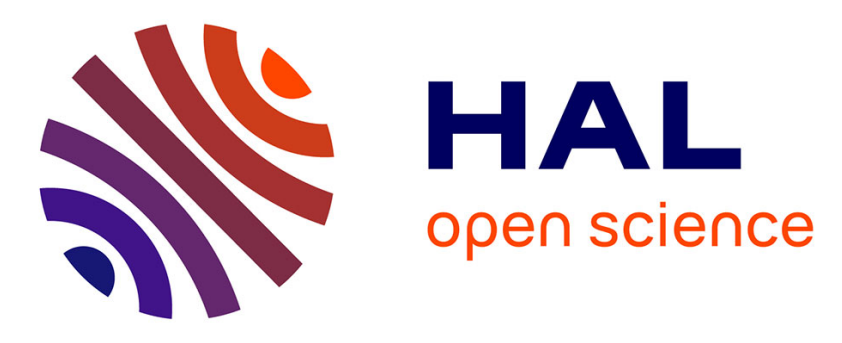

\title{
Evidencing the chemical degradation of a hydrophilized pes ultrafiltration membrane despite protein fouling
} Murielle Rabiller-Baudry, Aurélie Bouzin, Charlène Hallery, Jean Girard, Cindy Leperoux

\section{- To cite this version:}

Murielle Rabiller-Baudry, Aurélie Bouzin, Charlène Hallery, Jean Girard, Cindy Leperoux. Evidencing the chemical degradation of a hydrophilized pes ultrafiltration membrane despite protein fouling. Separation and Purification Technology, 2015, 147, pp.62-81. 10.1016/j.seppur.2015.03.056 . hal01141490

HAL Id: hal-01141490

https://hal-univ-rennes1.archives-ouvertes.fr/hal-01141490

Submitted on 4 Nov 2015

HAL is a multi-disciplinary open access archive for the deposit and dissemination of scientific research documents, whether they are published or not. The documents may come from teaching and research institutions in France or abroad, or from public or private research centers.
L'archive ouverte pluridisciplinaire HAL, est destinée au dépôt et à la diffusion de documents scientifiques de niveau recherche, publiés ou non, émanant des établissements d'enseignement et de recherche français ou étrangers, des laboratoires publics ou privés. 


\section{EVIDENCING THE CHEMICAL DEGRADATION OF A HYDROPHILIZED PES} ULTRAFILTRATION MEMBRANE DESPITE PROTEIN FOULING

Murielle RABILLER-BAUDRY*, Aurélie BOUZIN, Charlène HALLERY, Jean GIRARD, Cindy LEPEROUX

1-Université de Rennes 1, «Institut des Sciences Chimiques de Rennes » UMR-CNRS 6226, 263 avenue du Général Leclerc, CS 74205, case 1011, 35042 Rennes cedex, France

Corresponding author: murielle.rabiller-baudry@univ-rennes1.fr

\section{KEYWORDS}

PES, PVP, ultrafiltration, proteins, ageing, hypochlorite, FTIR-ATR

\section{ABSTRACT}

Hydrophilisation of polyethersulfone (PES) based membrane is often achieved by addition of polyvinylpyrrolidone (PVP) leading to a physical blend of the two polymers. This paper shows that the most commonly used membrane for UF in dairy industry is a PES/PVP based one. Nevertheless if hydrophilisation limits the organic fouling, PVP is also the Achilles heel of these membranes. It is particularly true when membranes are exposed to hypochlorite as it is the case for cleaning/disinfection steps. Evidencing the disappearance of PVP from a pristine PES/PVP membrane can be easily achieved by FTIR-ATR analyses. But when one wants to study the ageing of a membrane used in UF it gets more complicated: regardless of the cleaning efficiency the membrane always remains fouled by some proteins. As both PVP and proteins own chemical bounds leading to absorption at the same wavenumber in FTIRATR, it thereby prevents the easy highlighting of the PVP degradation. The aim of this paper is to propose a simple treatment of raw FTIR-ATR spectra to dissociate these two contributions, allowing consequently the study of the degradation of a fouled membrane. Then the procedure is applied to a real case study on a spiral membrane. 


\section{INTRODUCTION}

Fouling systematically occurs during ultrafiltration (UF) as it is observed when filtering skim milk by spiral membranes based on polyethersulfone (PES, Figure 1) [1-4]. The membrane composition is of course an important parameter as the physico-chemical interactions between the skim milk components and the membrane material play a crucial role on the membrane global fouling [5]. In fact, PES membranes also contained a minor amount of additives that are added to increase the membrane hydrophilic character, but generally these additives are not clearly mentioned by the membrane providers. Polyvinylpyrrolidone (PVP) (Figure 1) is one of the most famous used additive and it is quite logical to suspect its presence in a hydrophilised PES membrane. But it must generally be proved as it will be done in this study as preliminary investigation (see results).

Nowadays, it is quite well understood that hydrophilisation limits the membrane fouling by organic compounds such as proteins. Nevertheless, it is also known that PVP is the Achilles heel of these membranes. This is particularly true when they are exposed to sodium hypochlorite $(\mathrm{NaOCl})$ as it is the case for daily cleaning/disinfection steps at industrial scale.

To go ahead in the understanding in PES/PVP membrane stability, several teams working in membrane food or water applications have chosen to study variations of flux and selectivity after immersion of pristine membranes in various $\mathrm{NaOCl}$ solutions. For such purposes they used more or less complex degradation protocols $[\mathbf{2}, \mathbf{6}, \mathbf{8 - 2 2}]$.

Dealing with the membrane material degradation, in our opinion one of the most comprehensive fundamental results is obtained by infra-red analyses (FTIR). Infra-red spectroscopy is a technique only able to evidence polar bounds existing in polymers. Nevertheless it must be underlined that these studies are achieved on pristine membranes that were voluntary aged in sodium hypochlorite solutions, the $\mathrm{pH}$ of which is generally set in the range $8.0-9.0$. $\mathrm{NaOCl}$ disinfecting solutions having such $\mathrm{pHs}$ are known to be lead to severe degradation of PES/PVP membranes [see for instance 18, 19 and references cited herein]). In the case of PES/PVP membranes a special attention must be paid to an absorption band of the FTIR-ATR spectrum located close to a wavenumber at $1661 \mathrm{~cm}^{-1}$ and attributed to the $\mathrm{C}=\mathrm{O}$ amide bound of PVP. To put it in a nutshell, the PVP $\mathrm{C}=\mathrm{O}$ bound progressively disappears during the membrane ageing provoked by $\mathrm{NaOCl}$ treatments. Figure 2 shows one 
of the mechanism suggested in literature to explain the $\mathrm{C}=\mathrm{O}$ disappearance that can be understood as the opening of the PVP ring. This is significantly different from a total removal of the PVP or of its degradation compounds.

Moreover, another band located at $1030 \mathrm{~cm}^{-1}$ progressively appears on the FTIR-ATR spectrum and is commonly attributed to an evolution of the PES skeleton itself. Nevertheless there is still controversy about the exact meaning of this band, sometimes assigned to a sulfonic acid group $\left(\mathrm{SO}_{3} \mathrm{H}\right.$, Figure 3a, [14]) and recently to a phenol formation $(\mathrm{OH}$ on phenyl ring, Figure 3b, [18]). It is out of the scope of this paper to discuss the validity of these two proposal and in the following we will only discuss degradation of PES skeleton evidenced by the $1030 \mathrm{~cm}^{-1}$ band without any other comments.

To show the evolution of the PES skeleton is quite easy on an aged membrane that have been used at industrial scale because no band overlapping have been evidenced with the fouling (Figure 4) and the $1030 \mathrm{~cm}^{-1}$ is a pure signal revealing the PES degradation. For a more detailed presentation of the membrane used at industrial scale and called here "Membrane U" see $[\mathbf{1}]$.

The disappearance of PVP from a pristine PES/PVP membrane can be easily achieved by FTIR-ATR analysis, but only a single band can be used for this purpose: those located at 1661 $\mathrm{cm}^{-1}$. But when one wants to study the ageing of a membrane used in UF it gets more complicated because of the presence of fouling as it will be explained below.

Dealing with PES/PVP membranes fouled during UF of skim milk, it must be underlined that only a part of the whole fouling is irreversible (not removed by a simple water rinsing) and this part is known to be made of proteins only, in the particular case of organic membranes [34]. This irreversible protein deposit represents the target of the cleaning/disinfecting operation that immediately follows the production step. Classically, at industrial scale, organic UF membranes fouled by skim milk are cleaned according to a procedure involving a cascade of 3 solutions set at $50^{\circ} \mathrm{C}$ : alkaline cleaning at $\mathrm{pH}$ 11.5/12.0 with a formulated detergent containing surfactants, then acid cleaning generally with nitric acid at $\mathrm{pH} 1.6$ and finally an alkaline and chlorine disinfecting step using sodium hypochlorite (bleach) set at 150-200 ppm in total free chlorine (TFC) $[\mathbf{1}, \mathbf{3}, \mathbf{4}]$. In our previous studies we have explained how such a cascade can be simplified by the cancellation of the acid step [7]. Nevertheless for food security purposes it is not possible to withdraw the disinfecting step. Physico-chemical 
analyses of such industrial membranes autopsied at the end of their service life highlight presence of a residual protein fouling even after a final cleaning procedure [1].

Proteins own a specific bound called "amide I" ( $\mathrm{C}=\mathrm{O}$ vibration of the amide group, $-\mathrm{CO}-\mathrm{NH})$ that is superimposed to the PVP $\mathrm{C}=\mathrm{O}$ bound (the only one that can be used to deal with the PVP degradation). Consequently, an analytical difficulty must be overcome when fouling is made of proteins (Figure 5) to unambiguously evidence modifications of the membrane due to fouling occurrence or to membrane material degradation or a combination of the two. So in this paper we propose an approach to treat a FTIR-ATR spectrum in order to dissociate the contributions of PVP and proteins to the global band obtained on the raw spectrum of a fouled membrane. For the demonstration pristine membranes at 3 degradation states are prepared and fouled with proteins. Then the methodology is applied to the analysis of a spiral membrane $\left(6.7 \mathrm{~m}^{2}\right)$ used at laboratory scale alternatively in UF of skim milk and UF of sodium hypochlorite aiming at evidencing a possible heterogeneity of the membrane degradation with respect to the distribution of fouling in this complex geometry.

\section{THEORETICAL PART}

On the FTIR-ATR spectra of a PES/PVP pristine membrane (here HFK-131 membrane) all bands can be assigned to PES except that located at $1661 \mathrm{~cm}^{-1}$ which can be attributed to the $\mathrm{C}=\mathrm{O}$ bound of PVP. Figure 4 shows the attributions in the $1770-700 \mathrm{~cm}^{-1}$ range that is the range of interest for the following discussion. For sake of comparison, the spectrum of a membrane already used at industrial scale (Membrane $\mathrm{U}$ ) is also given. Membrane $\mathrm{U}$ is at the end of its service life that corresponds to $8,000 \mathrm{~h}$ of skim milk UF. A final and very efficient cleaning has been performed before the FTIR-ATR spectrum registration. As explained in the introduction, clearly the PVP $\mathrm{C}=\mathrm{O}$ band has disappeared and the new $1030 \mathrm{~cm}^{-1}$ band has appeared on the spectrum.

However, when the membrane is fouled by milk proteins and when the cleaning is not sufficiently efficient to remove the proteins from the membrane, the PVP $\mathrm{C}=\mathrm{O}$ band and the amide I band of proteins are overlapped. This analytical difficulty would be more and more frequent with the membrane ageing because the fouling tends to increase with the membrane age and the cleanability seems to decrease accordingly. Figure $\mathbf{5}$ shows the raw spectra obtained for a pristine membrane and for a protein fouled one. If the protein deposit is very 
high (see results) then an aged and fouled membrane can exhibit a $\mathrm{C}=\mathrm{O}$ band of greater intensity than that of the pristine membrane itself. Consequently it becomes impossible to deal with a possible degradation of PVP from the membrane without any treatment of the FTIR-ATR spectrum.

We propose to establish a mathematical treatment of the spectrum in order to dissociate the contribution of these two $\mathrm{C}=\mathrm{O}$ bands. Moreover, this paper aims at developing a simple approach that can be applied without any sophisticated and costly software able to perform band deconvolution.

Proteins also lead to a second characteristic absorption band called amide II band that corresponds to the superimposition of vibrations due to $\mathrm{CN}+\mathrm{NH}$ bounds of the amide group.

Knowing that the protein amide II band, located close to $1539 \mathrm{~cm}^{-1}$, have no overlapping with the pristine membrane bands, neither PES nor PVP, we have already developped a method of quantification of proteins directly on the HFK-131 membrane. This analysis is based on the $\mathrm{H}_{1539}$ protein amide II $/ \mathrm{H}_{1240}{ }^{\text {PES }}$ ratio (with $\mathrm{H}_{\mathrm{i}}^{\mathrm{X}}$ : band height corresponding to the absorbance intensity at a given $\mathrm{i}$ wavenumber $\left(\mathrm{w}_{\mathrm{i}}\right)$ and corresponding to $\mathrm{X}$ material or functional group) $[4]$.

The first step of the approach proposed in this paper is based on the simple fact that on a fouled membrane, absorption measured at $1661 \mathrm{~cm}^{-1}\left(\mathrm{H}_{1661}\right.$ raw spectrum $)$ corresponds to the superimposition of absorbance due to PVP $\left(\mathrm{H}_{1661}{ }^{\mathrm{PVP}}\right)$ and absorbance due to protein amide I vibration $\left(\mathrm{H}_{1661}\right.$ protein amide $\left.\mathrm{I}\right)$ :

$$
\mathrm{H}_{1661}{ }^{\text {raw spectrum }}=\mathrm{H}_{1661}{ }^{\mathrm{PVP}}+\mathrm{H}_{1661}{ }^{\text {protein amide } \mathrm{I}}
$$

The new idea of this paper consists in the determination of the protein amide I intensity at $1661 \mathrm{~cm}^{-1}\left(\mathrm{H}_{1661}\right.$ protein amide $\left.\mathrm{I}\right)$ from that of the amide II band $\left(\mathrm{H}_{1539}\right.$ protein amide II $)$. As mentioned previously, these two bonds belong to the same amide group, namely $\mathrm{N}-\mathrm{C}=\mathrm{O}$, but correspond to different vibration modes. Consequently it is not creasy to imagine that the intensity of the two FTIR bands of the amide group of proteins are correlated. Assuming this idea, we have tried to evidence the possible relationship between the two heights of these bounds without any other assumption. The experimental developments detailed in the results 
show that the relationship between the two heights exists. Moreover experimental results evidence that, regardless of the chosen protocol, the relationship is linear (see below). For sake of simplification the general form of this relationship is consequently given as that of a straight line (equation 2).

$$
\mathrm{H}_{1661} \text { protein amide I }=\alpha \mathrm{x} \mathrm{H}_{1539} \text { protein amide II }+\beta
$$

Where oand ßare coefficients to be determined.

A main bottleneck of the approach is the experimental determination of oand $\beta$ In the results we will discuss two experimental approaches to determine these coefficients. One is based on spectra acquired for proteins in aqueous solutions. The other involved treatment of spectra acquired with more or less aged membranes on which controlled protein deposit are made. It is explained in the results why only one of these two approaches can be validated.

The second key point is the experimental validation of equation 3 that can be easily drawn from the previous ones.

$$
\mathrm{H}_{1661} \text { raw spectrum } / \mathrm{H}_{1240}{ }^{\mathrm{PES}}=\left(\mathrm{H}_{1661} \mathrm{PVP} / \mathrm{H}_{1240}{ }^{\mathrm{PES}}\right)+\left(\mathrm{H}_{1661} \text { protein amide } \mathrm{I} / \mathrm{H}_{1240}{ }^{\mathrm{PES}}\right)
$$

It requires having PES/PVP membranes with various amount of PVP. In this paper we have used pristine and aged membranes specially prepared to cover a wide range of membrane degradation up to a PVP height divided by two with respect to its initial height.

Figure 6 summarizes the global approach.

\section{EXPERIMENTAL}

\subsubsection{Water, skim milk and solutions}

Water used either for solution preparation and membrane rinsing is deionised and $1 \mu \mathrm{m}$ filtered. Its conductivity is always lower than $1 \mu \mathrm{S} . \mathrm{cm}^{-1}$. 
The skim milk used is a commercial one (UHT, Lait de Montagne, Carrefour, France) containing an average of 32 g.L. $\mathrm{L}^{-1}$ proteins and 48 g.L. $\mathrm{L}^{-1}$ carbohydrates (mainly lactose) and only traces of lipids $(<0.5 \%)$.

Protein solutions are prepared from a powder containing whey proteins (PS90 Protarmor, Saint Brice en Coglès, France) dissolved in deionised water. A set of 6 concentrations is used: $0,5,10,20,30$ and 50 g.L $\mathrm{L}^{-1}$.

$\mathrm{NaOCl}$ solutions at $400 \mathrm{ppm}$ in total free chlorine (TFC) are prepared from commercial bleach solution provided by Lacroix (eau de Javel, bleach at 96,000 ppm TFC, France). The $\mathrm{pH}$ is adjusted to $8.0 \pm 0.1$ by addition of $\mathrm{HCl}$ of analytical grade (Acros).

A formulated alkaline solution, namely P3-ultrasil 10 provided by Ecolab (Issy les Moulineaux, France) is used for membrane cleaning. It is set at 4 g. $\mathrm{L}^{-1}$ that corresponds to a natural $\mathrm{pH}$ of 12.0 .

\subsubsection{Membranes}

The membrane used is named HFK-131. It is a UF membrane provided by Koch (USA) and commonly used at industrial scale for UF of skim milk and of both acid and rennet whey. This membrane represents about $70 \%$ of the world market for these specific applications. It is a PES based membrane of 5-10 $\mathrm{kg} \mathrm{mol}^{-1}$ molecular weight cut off according to the provider.

We have studied this membrane to prove that it is a PES/PVP one. Among experimental data allowing to draw this conclusion are:

(i) the presence of the $1661 \mathrm{~cm}^{-1}$ band on the FTIR-ATR spectra (Figure 4, Figure 5). Moreover, we had also checked that the HFK-131 spectrum is similar to that of a dense film we had prepared, that was made from PES and PVP physical blend (95/5) [6].

(ii) the presence of nitrogen evidenced by nano-SIMS measurements (Figure 7). SIMS is only able to evidence nitrogen atoms bounded to carbon further called organic nitrogen ( $\mathrm{CN}$ group). 


\subsubsection{Spiral membrane}

The spiral membrane is chosen in order to have a filtering area of several square meters (6.7 $\mathrm{m}^{2}$, $4333 \mathrm{~K} 131 \mathrm{VYV}$ module). The membrane (further called CIP-3, KMS K131V 8879759136 ) is made of 4 double sheets of membranes wounded around a permeate collector tube of 33 inches length as schematically explained in Figure 8.

\subsubsection{Flat membrane coupons: fouling of pristine and aged membranes}

Several flat membranes of $127 \mathrm{~cm}^{2}$ (or sometimes less) are sampled in a second pristine spiral membrane (further called cut-CIP-1). These membrane coupons are used for FTIR-ATR analyses performed to validate the methodological approach explained in the theoretical part. Prior to be used these samples are carefully rinsed in water to remove the preservative (the rinsing efficiency is systematically checked by FTIR-ATR).

\section{- Ageing of membrane coupons}

The ageing protocol is inspired from the one established in our laboratory and already described in [6]. Six membrane coupons $(6 \mathrm{~cm} \times 3 \mathrm{~cm})$ are soaked in a $\mathrm{NaOCl}$ solution set at $400 \mathrm{ppm}$ TFC and pH $8.0\left(\mathrm{~V}=26.3 \mathrm{~mL}\right.$, surface/volume $\left.=14.6 \mathrm{~L} . \mathrm{m}^{-2}\right)$ under micro-waves (pulsed microwaves at $255 \mathrm{~W}$ ) during 210 or $480 \mathrm{~min}$. The micro-waves help to accelerate the chemical degradation when compared to simple soaking in the same solution. Thus depending on the treatment duration different ageing states are reached; it is shown from the PVP C=O height decrease. In order to avoid impact of $\mathrm{NaOCl}$ concentration during the ageing process, the $\mathrm{NaOCl}$ solution has been regularly replaced by a similar volume of a fresh solution. Some characteristics of aged membranes are given Table $\mathbf{1}$.

\section{- Protein fouling of membrane coupons}

The protocol is the same when using pristine and aged membranes. A membrane coupon (3 $\mathrm{cm} \times 6 \mathrm{~cm}$ ) is immersed under gentle stirring at room temperature in $100 \mathrm{~mL}$ of a protein solution during $2 \mathrm{~h}$. Proteins are set at different concentrations $\left(0,5,10,20,30\right.$ and 50 g.L $\left.\mathrm{L}^{-1}\right)$. After dripping, membranes are carefully dried in a desiccator under dynamic vacuum. FTIR- 
ATR spectrum is registered on each dried coupon before and after the protein deposition. Protein quantification is achieved using equation 4 (see below). The amount of proteins on obtained deposit are shown Table $\mathbf{1}$ for the pristine membrane and the two aged membranes.

\subsubsection{UF with the spiral membrane}

\subsubsection{Skim milk $U F$}

A pristine spiral membrane is installed on a pilot provided by TIA (TIA 3093, Bollène, France) and already described in [24]. The fouling of the spiral membrane is achieved by UF of $24 \mathrm{~L}$ of skim milk at $50^{\circ} \mathrm{C}$ in batch mode at volume reduction ratio $\mathrm{VRR}=1$, meaning here that both the retentate and the permeate are fully recycled in the feed tank. During UF the feed flow rate is constant. It is set at $9.5 \mathrm{~m}^{3} \cdot \mathrm{h}^{-1}$ that corresponds to a cross-flow velocity of about $0.3 \mathrm{~m} \cdot \mathrm{s}^{-1}$.

The transmembrane pressure (TMP) is regularly increased from 1.5 bar at start to 4.0 bar at the end of the UF run. This last TMP value allows to reach the limiting flux. Each TMP increase is achieved when a plateau value of flux is reached at the previous TMP. The UF duration is close to $5.5 \mathrm{~h}$ for one UF run. The membrane flux $(\mathrm{J})$ is followed all over the skim milk UF.

The average TMP is classically calculated as the mean value when considering the membrane inlet and outlet TMPs. Nevertheless, it must be kept in mind that the pressure drop along the membrane element is 2.2 bar regardless of the average TMP. This is not a negligible value by comparison to the average TMP itself. In the following an estimation of the local TMP is made considering a linear pressure drop along the membrane element, according to a calculation proposed in $[\mathbf{2 3}]$.

At the end of skim milk UF, the membrane is extensively rinsed by water. Then it is cleaned at 2 bar, $50^{\circ} \mathrm{C}$ during $1 \mathrm{~h}$ by $25 \mathrm{~L}$ of P3-ultrasil 10 formulated solution. This protocol allows the water flux recovery of the pristine membrane.

\subsubsection{Sodium hypochlorite UF for membrane ageing}


In order to accelerate the spiral membrane ageing, UF of sodium hypochlorite solution at 400 ppm TFC and $\mathrm{pH} 8.0$ is performed at 2.0 bar and $50^{\circ} \mathrm{C}$. The treatment duration can vary and is summarized as a cumulative dose of hypochlorite expressed according to equation 5.

$$
\mathrm{NaOCl}_{\text {dose membrane exposition }}(\mathrm{ppm} . \mathrm{d})=400 \text { ppm x number of days } \quad(\text { eq. } 4)
$$

From a practical point of view, 3 UF of skim milk are consecutively performed on the pristine membrane. After alkaline cleaning the membrane is then aged in $\mathrm{NaOCl}$ up to a cumulative dose of 400 ppm.d. Then another UF of skim milk is performed. After a second alkaline cleaning the membrane is aged in $\mathrm{NaOCl}$ up to a cumulative dose of 2,000 ppm.d. Then another UF of skim milk is performed. After cleaning the membrane is aged up to a cumulative dose of 2,800 ppm.d and a final skim milk UF is performed. Finally, the membrane is carefully rinsed by water but not cleaned. Then the membrane is autopsied.

According to the provider this membrane is guaranteed up to a 5,000 ppm.d $\mathrm{NaOCl}$ dose but nothing is clearly explained about the way to reach this dose. Nevertheless, we can suggest that the autopsied CIP-3 membrane could be equivalent to a membrane close to half time of a normal service life at industrial scale.

\subsubsection{FTIR-ATR on membranes for protein quantification purpose}

The membrane samples are carefully dried under dynamic vacuum before registration to remove water (systematically checked in the $3500 \mathrm{~cm}^{-1}$ region).

For sake of generalization, three different FTIR-ATR spectrometers have been used in this study. Their characteristics are shown in Table $\mathbf{2}$ as well as the standard conditions used for spectra acquisition. It has been checked that the spectra acquired on each spectrometer are similar when dealing with the wavenumbers but the raw intensity of each band is different. This is probably due to differences in the ATR-accessory crystal (chemical nature and reflection number). Nevertheless it has also been checked that the relative ratio of two band heights (for instance: $\mathrm{H}_{\mathrm{i}} / \mathrm{H}_{1240}{ }^{\text {PES }}$ ) are the same regardless of the spectrometer used (see Figure A1 in Appendix 1). 


\subsubsection{Quantification of residual proteins directly on membranes}

The initial calibration has been established with spectrometer $1[3, \mathbf{4}, \mathbf{6}]$ but as explained above can be used with spectrometer 2 (see Figure A1 in Appendix 1) and spectrometer 3.

The quantification is possible in a wide range of fouling from 1 to $350 \mu \mathrm{g}$ of proteins per square centimetre of membrane (geometric area) with a precision of $1 \mu \mathrm{g} . \mathrm{cm}^{-2}$ (equation 4). 19 samples of fouled pristine membranes have been used to establish the equation, allowing to reach $r^{2}=0.997$.

$$
\mathrm{H}_{1539}{ }^{\text {protein amide II } / \mathrm{H}_{1240}}{ }^{\text {PES }}-\mathrm{H}_{2060-2240}{ }^{\text {baseline }}=0.0034[\mathrm{P}]
$$

With:

$[\mathrm{P}]$ : the protein concentration in $\mu \mathrm{g} . \mathrm{cm}^{-2}$

$\mathrm{H}_{\mathrm{i}}{ }^{\mathrm{X}}$ : band height corresponding to the absorbance intensity at a given wavenumber $\left(\mathrm{w}_{\mathrm{i}}\right)$ and corresponding to X material or functional group. (see Appendix 1).

$\mathrm{H}_{2060-2240}{ }^{\text {baseline }}$ : the average height of the baseline measured in the $2060-2240 \mathrm{~cm}^{-1}$ range of wavenumbers. Value equal to 0.0165 .

\section{- Specific procedure for the spiral membrane}

After the final fouling by skim milk up to 4.0 bar and rinsing by deionised water, the spiral membrane (CIP-3, $6.7 \mathrm{~m}^{2}$ ) has been cut in 324 pieces of about $127 \mathrm{~cm}^{2}$ area each.

Each flat sample is then analyzed with spectrometer 1. Only the spectrum of the sample center is registered. Nevertheless, each $127 \mathrm{~cm}^{2}$ sample could be divided in 9 smaller pieces of about $10 \mathrm{~cm}^{2}$ (corresponding to the ZnSe crystal area), but it has been checked on a whole membrane sheet of about $1 \mathrm{~m}^{2}$ that the variations are not significant and that a single result seems quite acceptable for the followed purpose.

This autopsy allows establishing firstly the mapping of the irreversible fouling and secondly that of the degradation state of the membrane by the mean of measurements at $1661 \mathrm{~cm}^{-1}$ (PVP) and $1030 \mathrm{~cm}^{-1}$ (PES skeleton).

- Specific procedure for the flat membrane coupons 
The small flat membrane coupons have been analyzed with spectrometer 2. It was used to establish the protocol exposed in the theoretical part above.

\subsubsection{FTIR-ATR on membranes for evidencing of membrane degradation}

Firstly the spectrum of each membrane coupon, in pristine form, is registered. Thus $\mathrm{H}_{1240}$ PES and $\mathrm{H}_{1661}{ }^{\mathrm{PVP}}$ is measured allowing the calculation of the $\mathrm{H}_{1661}{ }^{\mathrm{PVP}} / \mathrm{H}_{1240}{ }^{\mathrm{PES}}$ ratio for each sample.

Secondly, some membrane coupons are submitted to a more or less intensive ageing procedure according to the protocols described in paragraph 3.1.2. Then the spectrum of each aged membrane coupon is registered. Thus $\mathrm{H}_{1240}{ }^{\mathrm{PES}}$ and $\mathrm{H}_{1661}{ }^{\mathrm{PVP}}$ is measured allowing the calculation of the $\mathrm{H}_{1661}{ }^{\mathrm{PVP}} / \mathrm{H}_{1240}{ }^{\mathrm{PES}}$ ratio for each sample before fouling. Of course it has been checked that the PVP band is modified when compared to that measured before the ageing treatment. These values obtained after ageing are then used as reference values to be compared to values obtained after fouling on aged membranes.

Finally, membranes are fouled with protein solutions according to the protocol described in paragraph 3.1.2. FTIR-ATR spectra are then registered and $\mathrm{H}_{1661}{ }^{\text {raw spectra }}, \mathrm{H}_{1240}{ }^{\text {PES }}$ and $\mathrm{H}_{1661}$ protein amide II are determined for the registered spectrum of each membrane coupon after fouling allowing the acquisition of the raw spectra of aged then fouled membranes.

The following ratios, $\mathrm{H}_{1661}$ raw spectra $/ \mathrm{H}_{1240}{ }^{\text {PES }}$ and $\mathrm{H}_{1661}$ protein amide $\mathrm{II} / \mathrm{H}_{1240}{ }^{\text {PES }}$ can easily be deduced. Then $\mathrm{H}_{1661}$ protein amide $\mathrm{I} / \mathrm{H}_{1240}$ PES of the fouled membrane is drawn from equation 3 with the $\mathrm{H}_{1661}$ raw spectra $/ \mathrm{H}_{1240}{ }^{\mathrm{PES}}$ ratio of the fouled membrane and the $\mathrm{H}_{1661}{ }^{\mathrm{PVP}} / \mathrm{H}_{1240}{ }^{\mathrm{PES}}$ ratio of the same coupon before fouling.

Finally the $\mathrm{H}_{1661}$ protein amide $\mathrm{I} / \mathrm{H}_{1661}$ protein amide II ratio is obtained from the $\left(\mathrm{H}_{1661}\right.$ protein amide

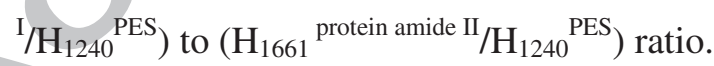

\subsubsection{FTIR-ATR on protein solutions}

Spectra of $1 \mu \mathrm{L}$ of the several protein solutions have been registered with spectrometer 2 . 
The obtained spectrum of a solution (Protein raw spectrum) is the superimposition of the water spectrum and of the protein one. But because the main component of a protein solution is water that have a band located at $1637 \mathrm{~cm}^{-1}$ which overlaps the amide I band of proteins, a treatment of the raw spectrum is needed to put in evidence amide I and amide II bands of proteins (Equation 6, see Appendix 2 for details). After treatment the spectrum is called Protein difference spectrum

Protein difference spectrum $=$ Protein raw spectrum $-\gamma$ water spectrum (eq. 6)

With:

$\gamma$ coefficient to be determined for each protein spectrum. The determination of $\gamma$ is based on the cancellation of the $\mathrm{OH}$ band of water located close to $3300 \mathrm{~cm}^{-1}$. There is no significant overlapping of the $3300 \mathrm{~cm}^{-1}$ water band with protein bands in this region, because unsaturated $\mathrm{C}-\mathrm{H}$ bonds of proteins are located below $3000 \mathrm{~cm}^{-1}$. The determination of $\gamma$ is the result of tests and errors with different values close to 1.000 with the objective to obtain a a region close to $3300 \mathrm{~cm}^{-1}$ as flat as possible in the Protein difference spectrum that is the considered criterion to prove the quality of the spectrum treatment. Moreover, for similar reason, the $2300-1800 \mathrm{~cm}^{-1}$ region must also be as flat as possible on the difference spectrum (see Appendix 2 for details). From a practical point of view, in this study $\gamma$ slightly varies around $0.8 \pm 0.2$.

\section{RESULTS AND DISCUSSION}

\subsection{FTIR-ATR study of estimation of protein amide I band from protein amide II band}

As already explained the first bottleneck of the procedure (Figure 6) consists in the estimation of protein amide I intensity from that of protein amide II on the FTIR-ATR spectrum. Two approaches have been tested that are detailed in the following.

\subsubsection{Proteins in solution}

Spectra of $1 \mu \mathrm{L}$ of several protein solutions have been registered with spectrometer 2. Spectra have then been post-treated according to the procedure described in paragraph 3.1.6. 
The results evidence that the $\mathrm{H}_{1661}$ protein amide I $/ \mathrm{H}_{1539}$ protein amide II ratio decreases linearly with protein concentration according to equation 7 .

$$
\mathrm{H}_{1661} \text { protein amide I } / \mathrm{H}_{1539} \text { protein amide II }=-0.06 \times\left[\mathrm{P}^{\prime}\right]+3.6 \quad \text { with } \mathrm{r}^{2}=0.95 \quad \text { (eq. 7) }
$$

With:

$\left[\mathrm{P}^{\prime}\right]$ the concentration of proteins in $\mathrm{g} . \mathrm{L}^{-1}$

This linear trend suggests a structural evolution of proteins with dilution.

\subsubsection{Proteins adsorbed on flat membrane}

Spectra of voluntary aged and fouled membrane coupons have been registered with spectrometer 1 . Then spectra have been post-treated according to the procedure described in paragraph 3.1.5.

Table 3, Table 4 and Table 5 present FTIR-ATR data before and after fouling by proteins on the pristine membrane and the two aged ones.

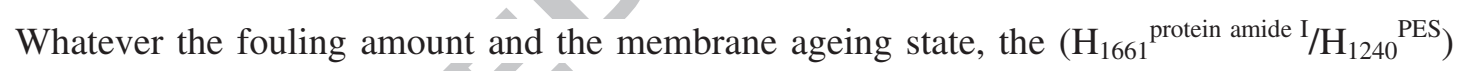

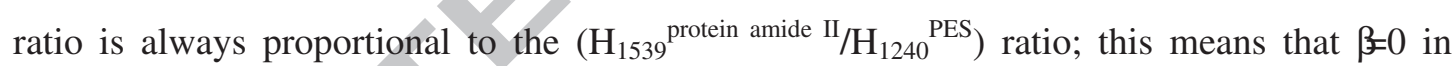
equation 2.

Moreover, the $\left(\mathrm{H}_{1661}\right.$ protein amide I $/ \mathrm{H}_{1539}$ protein amide II $)$ ratio, and thus oterm of equation 2 , is the same for the three aged state membranes in a wide range of protein deposit amount. (Table 6).

\subsubsection{Conclusion on the two approaches}

Estimation of the height of protein amide I band from the height of protein amide II band can be achieved from spectra acquired with proteins in solution and with proteins adsorbed on membranes. Nevertheless the conclusions are clearly different: in solution the ratio of the two band heights varies whereas it remains constant for proteins adsorbed on membranes. 
In solution, this result suggests a structural evolution of proteins with dilution likely due to a competition between hydrogen bond due to protein-protein interactions and those due to protein-water interactions.

On membranes, adsorption is mainly due to hydrophobic interactions that lead to similar structures of adsorbed proteins, regardless of the amount that always remains low.

Finally the proposed approach can be validated by using calibration obtained with protein adsorbed on membranes because it is a closer situation to that of adsorbed proteins during UF (Table 6).

\subsection{Spiral membrane degradation state}

The degradation state is discussed from both flux measurements and FTIR-ATR spectra.

\subsubsection{UF of skim milk}

For pristine CIP-3 membrane, the permeability to water at $50{ }^{\circ} \mathrm{C}$ is $59.8 \mathrm{~L} \cdot \mathrm{h}^{-1} \cdot \mathrm{m}^{-2} \cdot \mathrm{bar}^{-1}$.

Three UF of skim milk have been performed on the pristine membrane with an alkaline cleaning step between each of them. Figure 9 shows the excellent reproducibility.

After a sufficient dose of $\mathrm{NaOCl}$ received by the membrane, fluxes progressively increase, highlighting, on a hydrodynamic point of view, that membrane degradation occurs. It is also evidenced that more than the limiting flux the critical flux also varies with the membrane ageing (see [24] and references cited herein for a discussion dealing with limiting and critical fluxes with the pristine membrane in skim milk).

\subsubsection{Mapping of the protein irreversible deposit}

After the last skim milk UF ( $\mathrm{NaOCl}$ dose set at 2,800 ppm.d) the membrane is rinsed and autopsied. Figure $\mathbf{1 0}$ shows the distribution of the residual protein amount according to the location on the eight membrane sheets (supporting values are given Figure A4-1 in Appendix 
4). The zone closed to the permeate collector axis is often more fouled. An average value is calculated on all the membrane and corresponds to $50 \pm 9 \mu \mathrm{g} . \mathrm{cm}^{-2}$.

\subsubsection{PVP distribution on aged and fouled membrane}

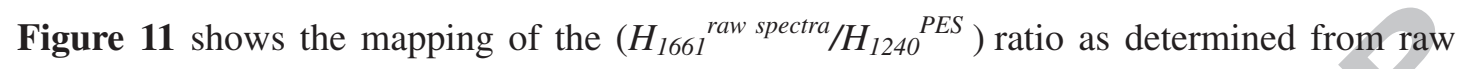
spectra obtained by FTIR-ATR. An average ratio is calculated on the whole membrane corresponding to $0.24 \pm 0.03$ ( $\mathrm{RSD}=11 \%$, the supporting values can be seen in Figure A4-2 in Appendix 4).

Figure 12 shows the mapping of the $\left(H_{1661}^{P V P} / H_{1240}{ }^{P E S}\right)$ ratio as determined from raw spectra obtained by FTIR-ATR and applying equation 3. An average ratio is calculated on the whole membrane corresponding to $0.08 \pm 0.02$ ( $\mathrm{RSD}=18 \%$, the supporting values can be seen in Figure A4-3 in Appendix 4). The PVP amount can be roughly considered as constant, highlighting a regular, but not total, disappearance of PVP on the whole membrane. This value is between that of the pristine membrane (0.14) and that of the industrial aged membrane (membrane $\mathrm{U}$ after extensive cleaning, 0.06).

In this spiral membrane, the protein amount varies from 10 to $80 \mu \mathrm{g}$ of proteins per $\mathrm{cm}^{2}$ but most values are in the range $40-60 \mu \mathrm{g} \cdot \mathrm{cm}^{-2}$ : fouling is not homogeneous whereas the PVP amount appears roughly constant. Consequently it is not possible to evidence if the protein fouling plays a protective role toward the PVP degradation. Nevertheless it is not possible to conclude on the absence of this protection.

\subsubsection{PES degradation on aged and fouled membrane}

PES degradation has been checked from the $1030 \mathrm{~cm}^{-1}$ band increase. Figure 13 shows the mapping of the $\left(H_{1030} / H_{1240}{ }^{P E S}\right)$ ratio as determined from raw spectra obtained by FTIR-ATR. $\mathrm{An}$ average ratio has been calculated on the whole membrane corresponding to $0.13 \pm 0.06$ even if the relative standard deviation is very high ( $\mathrm{RSD}=45 \%$, the supporting values can be seen in Figure A4-4 in Appendix 4). Consequently, this degradation state cannot be considered as constant and further investigations are needed to understand the origin of this observation. Nevertheless all these values are significantly lower than that of the industrial aged membrane (Membrane $\mathrm{U}$ after extensive cleaning, 0.29). 
For similar reasons, it is not possible to evidence if the protein fouling plays or not a protective role toward the PES degradation.

Prulho et al. [19] and Pellegrin et al. [20] suggesteed a link between PVP degradation and PES degradation. These authors believe that some degradation compounds of PVP obtained from reaction involving $\mathrm{NaOCl}$ can be active organic radicals. These radicals would be able to attack the PES skeleton and lead to the $1030 \mathrm{~cm}^{-1}$ band. So we tried to find correlation between PVP disappearance $\left(\mathrm{H}_{1661}{ }^{\mathrm{PVP}} / \mathrm{H}_{1240}{ }^{\mathrm{PES}}\right)$ and PES degradation $\left(\mathrm{H}_{1030} / \mathrm{H}_{1240}{ }^{\mathrm{PES}}\right)$. But no particular relationship was found (see Figure A3-1 in Appendix 3). Our results were not able to confirm nor infirm the assumption of these authors.

\section{CONCLUSION}

This paper proposes and validates an approach to evaluate the degradation state of a PES/PVP membrane even when the membrane is fouled by proteins.

The procedure is based on FTIR-ATR technique and can be used with spectrometers of different characteristics aiming at a generalization of these results.

The approach is then successfully applied to a case study of a spiral membrane voluntarily aged on a UF pilot by filtration of a $400 \mathrm{ppm} \mathrm{NaOCl} \mathrm{pH} 8.0$ solution alternatively with UF of skim milk.

Mapping of the irreversible fouling distribution in this membrane aged at 2,800 ppm.d NaOCl dose has been performed. The results demonstrate the existence of a protein distribution that is different from that observed at lower TMP with a pristine membrane [24]. The PVP remaining amount is quite regular showing a partial degradation but not a total disappearance. The PES skeleton is also degraded but in a more irregular way. An attempt of correlation between protein fouling and PVP disappearance or PES degradation failed. Nevertheless it is not possible to draw conclusion about the efficiency or the non-efficiency of protection of the fouling layer toward the whole process of membrane degradation. Moreover, it has not been possible to evidence a link between PVP disappearance and PES skeleton degradation. 


\section{ACKNOWLEDGEMENTS}

This study was financially supported by the French ANR program "Méduse" (project $\mathrm{n}^{\circ}$ ANR-09-BLAN-0055-01).

The authors acknowledge Thomas DELHAYE, from University of Rennes 1 (Nanosims Platform) for the SIMS analysis of the pristine membrane.

The authors acknowledge Frederic Bon from University of Rennes 1- IUT Rennes for discussion. 


\section{REFERENCES}

[1] L. Begoin, M. Rabiller-Baudry, B. Chaufer, C. Faille, P. Blanpain-Avet, T. Benezech, T.A. Doneva, Methodology of analysis of a spiral wound module. Application to PES membrane of ultrafiltration of skimmed milk, Desalination 192 (2006) 40-53.

[2] L. Begoin, M. Rabiller-Baudry, B. Chaufer, M.C. Hautbois, T.A. Doneva, Ageing of PES industrial spiral-wound membranes in acid whey ultrafiltration, Desalination 192 (2006) 2539.

[3] M. Rabiller-Baudry, L. Bégoin, D. Delaunay, L. Paugam, B. Chaufer, A dual approach of membrane cleaning based on physico-chemistry and hydrodynamics: Application to PES membrane of dairy industry, Chem. Eng. Process. 47 (2008) 267-275.

[4] D. Delaunay, M. Rabiller-Baudry, J.M. Gozalvez-Zafrilla, B. Balannec, M. Frappart, L. Paugam, Mapping of protein fouling by FTIR-ATR as experimental tool to study membrane fouling and fluid velocity profile in various geometries and validation by CFD simulation, Chem. Eng. Process. 47 (2008) 1106-1117.

[5] H. Bouzid, M. Rabiller-Baudry, L. Paugam,F. Rousseau, Z. Derriche, N.E. Bettahar, Impact of zeta potential and size of caseins as precursors of fouling deposit on limiting and critical fluxes in spiral ultrafiltration of modified skim milks, J. Membr. Sci. 314 (2008) 6775.

[6] M. Rabiller-Baudry, C. Leperoux, D. Delaunay, H. Diallo, L. Paquin, On the use of microwaves to accelerate ageing of an ultrafiltration PES membrane by sodium hypochlorite to obtain similar ageing state to that obtained for membranes working at industrial scale, Filtration 14 (2014) 38-48.

[7] L. Paugam, D. Delaunay, N.W. Diagne, M. Rabiller-Baudry, Cleaning of skim milk PES ultrafiltration membrane: on the real effect of the cleaning acid step, J. Membr. Sci. 428 (2013) 275-280. 
[8] C. Causserand, S. Rouaix, J.P. Lafaille, P. Aimar, Degradation of polysulfone membranes due to contact with bleaching solution, Desalination 199 (2006) 70-72.

[9] S. Rouaix, C. Causserand, P. Aimar, Experimental study of the effects of hypochlorite on polysulfone membrane properties, J. Membr. Sci. 277 (2006) 137-147.

[10] F. Thominette, O Farnault, E. Gaudichet-Maurin, C. Machinal, J.C. Schrotter, Ageing of polyethersulfone ultrafiltration membranes in hypochlorite treatment, Desalination 200 (2006) 7-8.

[11] E. Gaudichet-Maurin, F. Thominette, Ageing of polysulfone ultrafiltration membranes in contact with bleach solutions, J. Membr. Sci. 282 (2006) 198-204.

[12] E. Arkhangelsky, D. Kuzmenko, V. Gitis, Impact of chemical cleaning on properties_and functioning of polyethersulfone membranes, J. Membr. Sci.305 (2007) 176-184.

[13] C. Causserand, S. Rouaix, J.P. Lafaille; P. Aimar, Ageing of polysulfone membranes in contact with bleach solution: Role of radical oxidation and of some dissolved metal ions, Chem. Eng. Process.: Process Intensification 47 (2008) 48-56.

[14] K. Yadav, K.R. Morison, M.P. Staiger, Effects of hypochlorite treatment on the surface morphology and mechanical properties of polyethersulfone ultrafiltration membranes, Polymer Degrad. Stab. 94 (2009) 1955-1961.

[15] K. Yadav, K.R. Morison, Effects of hypochlorite exposure on flux through polyethersulphone ultrafiltration membranes, Food Bioproducts Process. 88 (2010) 419-424.

[16] B. Pellegrin, R Prulho, A. Rivaton, S. Therias, J.L. Gardette, E. Gaudichet-Maurin, C. Causserand, Hypochlorite Cleaning of Polyethersulfone/Polyvinylpyrrolidone Ultrafiltration Membranes: Impact on Performances, Procedia Engineering 44 (2012) 472-475.

[17] R. Prulho, A. Rivaton, S. Therias, J.L. Gardette, Ageing Mechanism of Polyethersulfone/Polyvinylpyrrolidone Membranes in Contact with Bleach Water, Procedia Engineering 44 (2012) 1031-1034. 
[18] R. Prulho, S. Therias, A. Rivaton, J.L. Gardette, Ageing of polyethersulfone/polyvinylpyrrolidone blends in contact with bleach water, Polymer Degrad. Stabi. 98 (2013) 1164-1172.

[19] B. Pellegrin, R. Prulho, A. Rivaton, S. Therias, J.L. Gardette, E. Gaudichet-Maurin, C. Causserand, Multi-scale analysis of hypochlorite induced PES/PVP ultrafiltration membranes degradation, J. Membr. Sci. 447 (2013) 287-296.

[20] C. Régula, E. Carretier, Y. Wyart, M. Sergent, G. Gésan-Guiziou, D. Ferry, A. Vincent, D. Boudot, P. Moulin, Ageing of ultrafiltration membranes in contact with sodium hypochlorite and commercial oxidant: Experimental designs as a new ageing protocol, Sep. Purif. Technol. 103 (2013) 119-138.

[21] C. Regula, E. Carretier, Y. Wyart, G. Gésan-Guiziou, A. Vincent, D. Boudot, P. Moulin, Chemical cleaning/disinfection and ageing of organic UF membranes: A review, Water Res.56 (2014) 325-365.

[22] I.M. Wienk, E.E.B. Meuleman, Z Borneman, Th. van den Boomgaard, C.A. Smolders, Chemical treatment of membranes of a polymer blend: mechanism of the reaction of hypochloride with poly(vinylpyrrolidone). J. Polym. Sci.: Part A: Polym. Chem. 33 (1995) 49-54.

[23] M. Rabiller-Baudry, N.W Diagne, D. Lebordais, How the experimental knowledge of the irreversible fouling distribution can contribute to understand the fluid circulation in a spiral ultrafiltration membrane, Sep. Purif. Technol. 136 (2014) 157-167. 


\section{Table captions}

Table 1. Conditions of membrane accelerated ageing, FTIR-ATR characteristics and protein amount further adsorbed on (aged) membrane surface.

${ }^{*} \mathrm{H}_{1661}{ }^{\mathrm{PVP}}$ is the height of the band located at $1661 \mathrm{~cm}^{-1}$ and attributed to PVP in the pristine membrane whereas $\mathrm{H}_{1240}{ }^{\text {PES }}$ is the height of the band located at $1240 \mathrm{~cm}^{-1}$ and attributed to PES in the pristine membrane.

Table 2. Description of the 3 FTIR-ATR spectrometers used in this study

Table 3. $\mathrm{H}_{\mathrm{i}} / \mathrm{H}_{1240}{ }^{\text {PES }}$ ratio from FTIR-ATR before and after fouling of pristine membrane by proteins.

Table 4. $\mathrm{H}_{\mathrm{i}} / \mathrm{H}_{1240}{ }^{\text {PES }}$ ratio from FTIR-ATR before and after fouling of the $210 \mathrm{~min}$ microwaves aged membrane by proteins.

Table 5. $\mathrm{H}_{\mathrm{i}} / \mathrm{H}_{1240}{ }^{\text {PES }}$ ratio from FTIR-ATR before and after fouling of the 480 min microwaves aged membrane by proteins

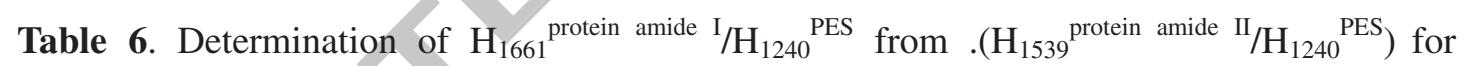
different membranes 


\section{Figure captions}

Figure 1: Some polymers constituting active layer of membranes

Figure 2: Opening of the PVP ring opening by hypochlorite in alkaline conditions according to Wienk et al. [22]

Figure 3: Evolution of PES skeleton by formation of - (a) sulfonic acid group according to [14] and (b) phenol group (OH on the phenyl ring) according to [18]

Figure 4: FTIR-ATR raw spectra of a pristine PES/PVP membrane (HFK-131, Koch) in green and with smaller intensity of an industrial membrane at the end of its service life (membrane U)

Figure 5: Raw spectra of a PES/PVP membrane - (a) without or (b) with protein fouling

Figure 6: Summary of the analytical difficulty to overcome and of the proposed approach

Figure 7: NanoSIMS analysis of the pristine HFK-131 membrane highlighting presence of nitrogen. Y-axis gives the atomic ratio of organic nitrogen to sulfur considering that $\mathrm{N}$ comes from PVP and S from PES. The longer is the atom ablation time on the $\mathrm{x}$-axis the deeper is the analysis in the membrane. There is more PVP on the surface of the membrane but it never disappears

Figure 8. Scheme of the spiral membrane with 4 double sheets highlighting the different channels in which are inserted retentate or permeate spacer, respectively. Each membrane is labelled according to the same nomenclature as those used for the quantification of protein amount for the autopsied membrane (see results). F1C1 is the innermost membrane sheet whereas $\mathrm{F} 4 \mathrm{C} 2$ is the outermost one. 
Figure 9: Evolution of flux in skim milk according to $\mathrm{NaOCl}$ dose received by the spiral membrane

Figure 10. Mapping of the protein irreversible deposit in the spiral membrane determined from FTIR-ATR quantification (protein amount in $\mu \mathrm{g} . \mathrm{cm}^{-2}$ ) according to the location in the spiral membrane. The local TMP is calculated from the assumption of a linear pressure drop decrease. The membrane labels are defined on Figure 8. TMP decreases from the inlet to the outlet of the spiral membrane. $d$ is the distance from the permeate axis $(d=0)$ for a membrane sheet.

Figure 11 Mapping of $\mathrm{H}_{1661}$ raw spectrum/ $\mathrm{H}_{1240}$ PES obtained from FTIR-ATR according to the location in the spiral membrane. The local TMP is calculated from the assumption of a linear pressure drop decrease. The membrane labels are defined on Figure 8. TMP decreases from the inlet to the outlet of the spiral membrane. $d$ is the distance from the permeate axis $(d=0)$ for a membrane sheet.

Figure 12. Mapping of $\mathrm{H}_{1661}{ }^{\mathrm{PVP}} / \mathrm{H}_{1240}{ }^{\mathrm{PES}}$ obtained from equation 3 according to the location in the spiral membrane. The local TMP is calculated from the assumption of a linear pressure drop decrease. The membrane labels are defined on Figure 8. TMP decreases from the inlet to the outlet of the spiral membrane. $d$ is the distance from the permeate axis $(d=0)$ for a membrane sheet

Figure 13. Mapping of $\mathrm{H}_{1030} / \mathrm{H}_{1240}$ PES according to the location in the spiral membrane. The local TMP is calculated from the assumption of a linear pressure drop decrease. The membrane labels are defined on Figure 8. TMP decreases from the inlet to the outlet of the spiral membrane. $\mathrm{d}$ is the distance from the permeate axis $(\mathrm{d}=0)$ for a membrane sheet 


\section{APPENDICES}

\section{Appendix 1: FTIR-ATR registration}

One must understand that the penetration depth of the IR incident beam in the membrane depends on the thickness of the fouling deposit. Consequently direct comparison of $\mathrm{H}_{\mathrm{i}}$ on two spectra with different fouling amounts is not possible.

To overcome this difficulty, we pay a special attention to one of the PES membrane bands, those located at $1240 \mathrm{~cm}^{-1}$ (the height of which is further called $\mathrm{H}_{1240}{ }^{\text {PES }}$ ). This band has no overlapping with PVP and protein bands. Consequently it can be used as a reference band.

We then need to determine the $\mathrm{H}_{\mathrm{i}} / \mathrm{H}_{1240}{ }^{\text {PES }}$ ratio to compare variation in the quantity of the target component owing a band located at $\mathrm{w}_{\mathrm{i}}$.

On a practical point of view $\mathrm{H}_{\mathrm{i}}$ has to be measured against a baseline of reference that must be chosen in a wavenumber region that is very flat and with a very small absorbance, for instance between 2240 and $2060 \mathrm{~cm}^{-1}$ further called $\mathrm{H}_{2060-2240}{ }^{\text {baseline }}$ with spectrometer 1 .

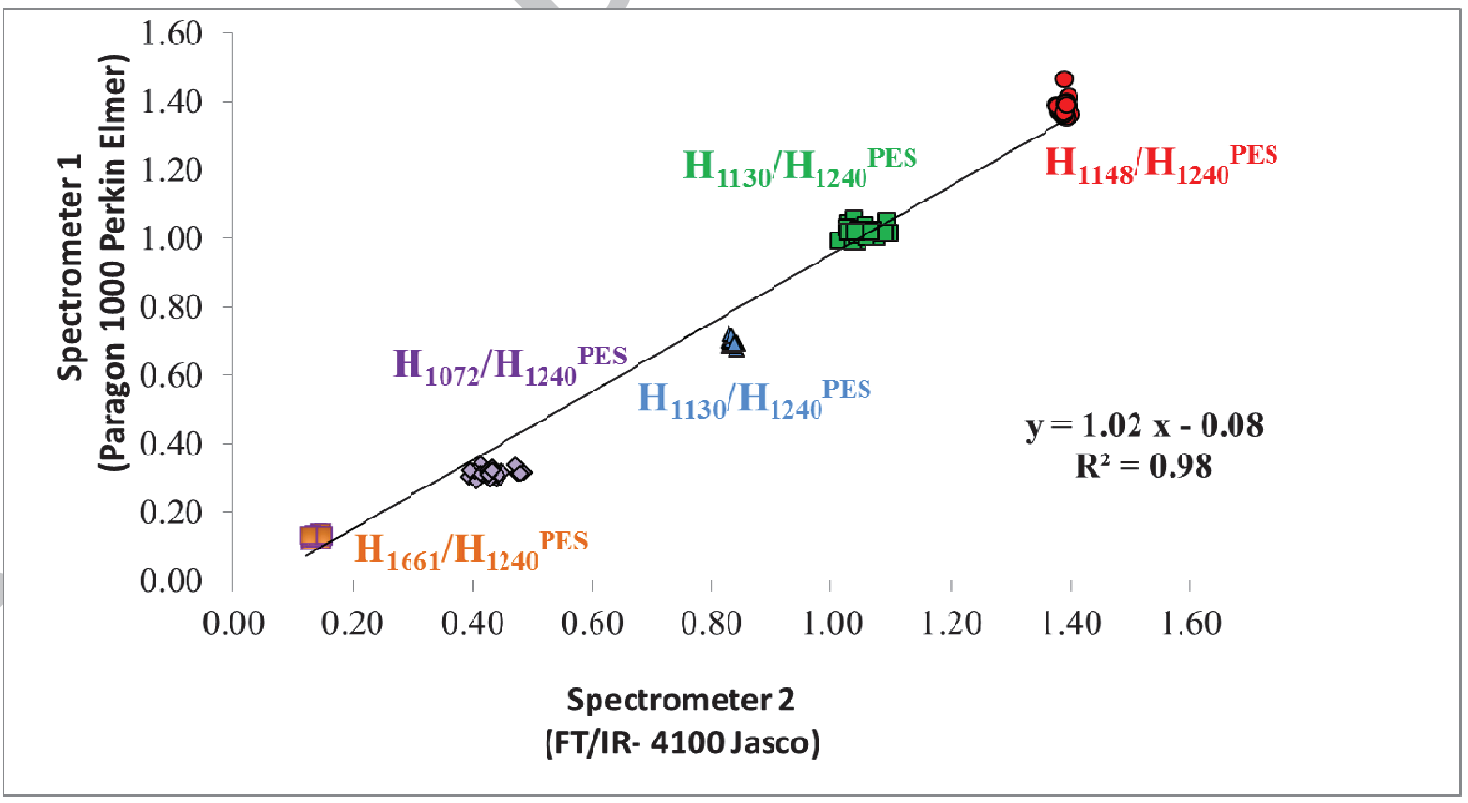

Figure A1-1: Linear relationship between band height ratio $\left(H_{i} / H_{1240}{ }^{P E S}\right)$ measured on different pristine HFK-131 membranes with spectrometer 1 and spectrometer 2. Similar results are obtained when comparing spectrometer 1 and spectrometer 3. 


\section{Appendix 2: Determination of $\gamma$ for FTIR-ATR analysis of proteins in aqueous solutions.}

The spectrum of water is firstly registered (Figure A2-1 a): two main bands due to $\mathrm{OH}$ bond are observed located close to $3333 \mathrm{~cm}^{-1}$ and $1636 \mathrm{~cm}^{-1}$, respectively.

(a)

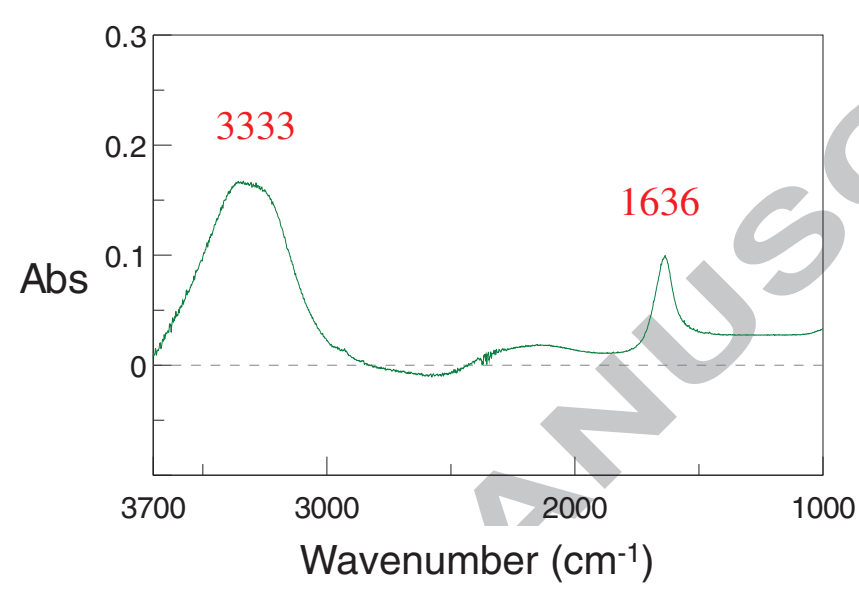

(b)

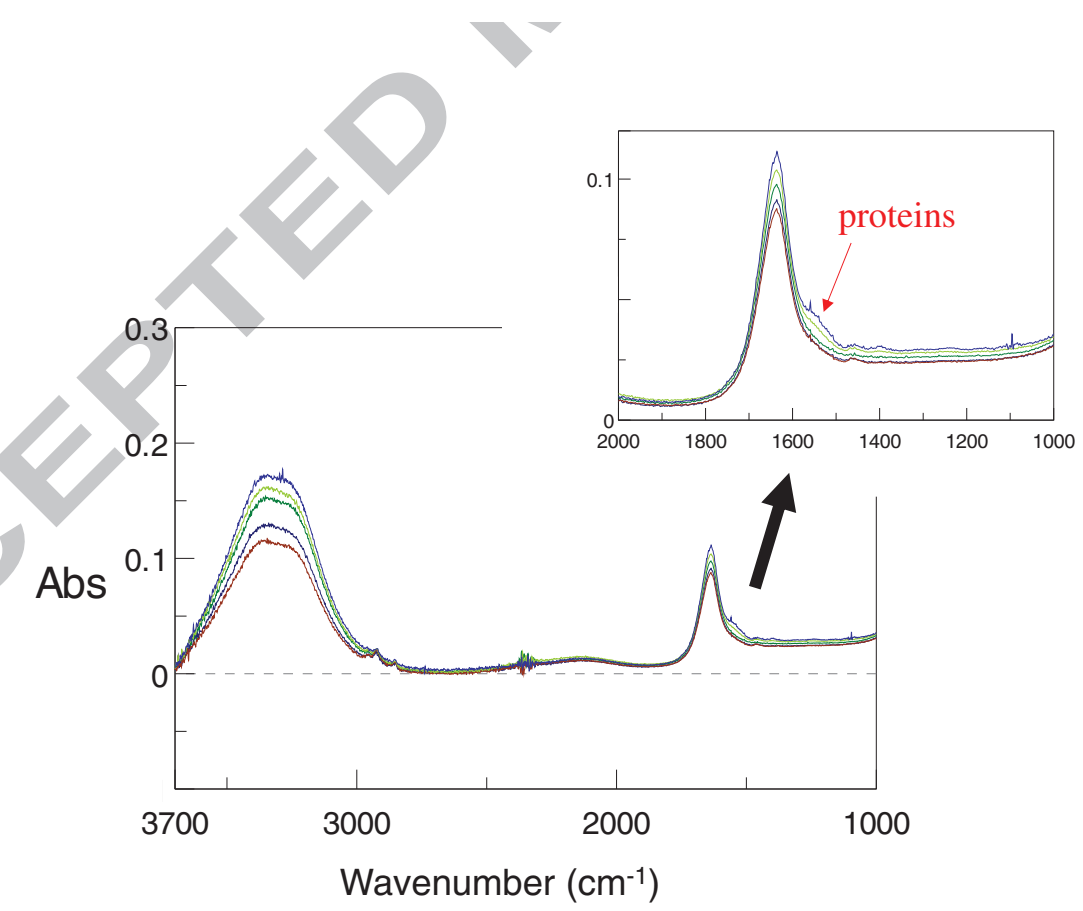

Figure A2-1: FTIR-ATR raw spectra- (a) water - (b) protein solutions in water

The spectra of protein solutions (protein concentration between 5 and 50 g. $\mathrm{L}^{-1}$ ) are registered

(Figure A2-1 b). At first sight bands of water are easily observed. Looking carefully close to 
$1500-1600 \mathrm{~cm}^{-1}$, it is shown that shoulders appear in the $1636 \mathrm{~cm}^{-1}$ band of water. These shoulder correspond to amide I and amide II band of proteins, as it can be evidenced after substraction according to equation A2-1 (Figure A2-2b).

(a)

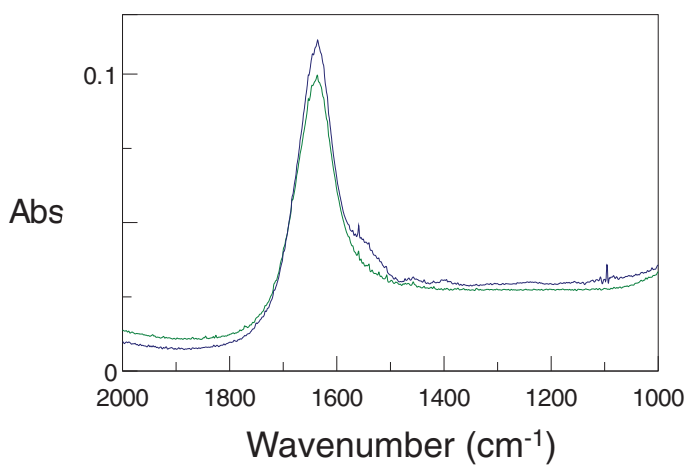

(b)

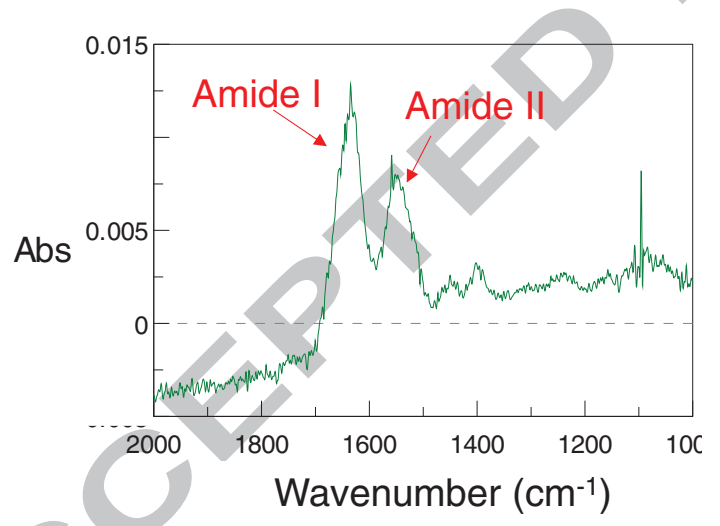


Figure A1-2: FTIR-ATR spectra in the 2000-1000 $\mathrm{cm}^{-1}$ region. (a) raw spectra of water and protein solution at $50 \mathrm{~g} \cdot \mathrm{L}^{-1}-(\mathrm{b})$ difference spectrum obtained according to equation A2-1.

The use of equation A2-1 is correct as a first estimation and for qualitative purpose. But in order to have a better accuracy on the height of protein bands for quantitative purpose, the equation must be modified by introducing a corrective term, further called $\gamma$ leading at least to equation A2-2 (similar to eq. 6 in the full paper).

Protein difference spectrum $=$ Protein raw spectrum $-\gamma$ water spectrum $\quad($ eq. A2-2 $)$

The value of $\gamma$ is determined from the simultaneous cancellation of both the 3333 and 1636 $\mathrm{cm}^{-1}$ bands of the raw spectra attributed to water. Figure A2-3 illustrates the impact of $\gamma$ choice that is adjusted up to obtain a difference spectrum as flat as possible in the regions of interest.

(a)

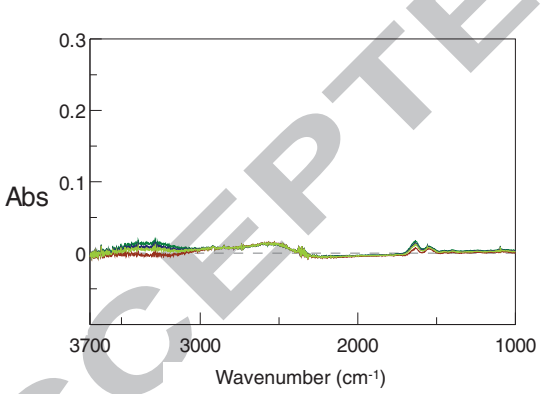

(b) 


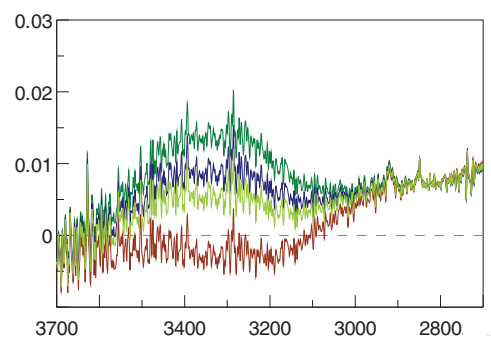

(c)

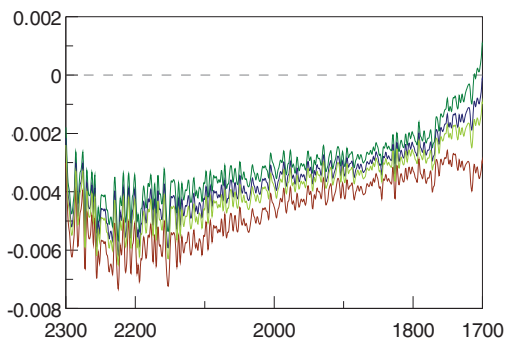

(d)

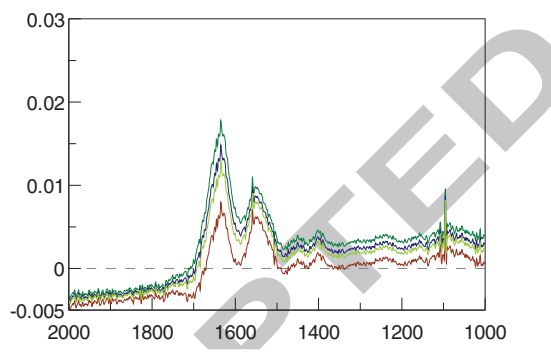

Figure A2-3: FTIR-ATR difference spectra obtained from protein solution spectrum (50 g.L $L^{-1}$ ) and water spectrum according to equation $\mathbf{A} 2$ with various walue in the range $0.95-1.05$ (a) $3700-1000 \mathrm{~cm}^{-1}$ range- (b) zoom in the $3700-2800 \mathrm{~cm}^{-1}$ region to evidence cancellation of the $3333 \mathrm{~cm}^{-1}$ water band $-(c)$ zoom in the $2300-1700 \mathrm{~cm}^{-1}$ region and (d) zoom in the 2000$1000 \mathrm{~cm}^{-1}$ region to evidence cancellation of the $1661 \mathrm{~cm}^{-1}$ water band and the appearance of amide I and amide II protein bands.

Such determination have been done for the different protein concentration. Table A2-1 shows the optimized $\gamma$ values for spectrum used in this study. 
Table A2-1. Optimised $\gamma$ value for difference spectrum (according to equation A2) for each protein solution. :

\begin{tabular}{|c|c|}
\hline $\begin{array}{c}\text { Protein } \\
\text { concentration } \\
\left(\mathrm{g} . \mathrm{L}^{-1}\right)\end{array}$ & $\gamma$ \\
\hline 5 & 0.920 \\
\hline 10 & 0.800 \\
\hline 20 & 0.699 \\
\hline 30 & 0.780 \\
\hline 50 & 1.018 \\
\hline
\end{tabular}

Appendix 3: Attempt of correlation between PVP and PES degradation

The aim is to evidence possible correlation between the disappearance of PVP and the degradation of PES (Figure A3-1). None is found.

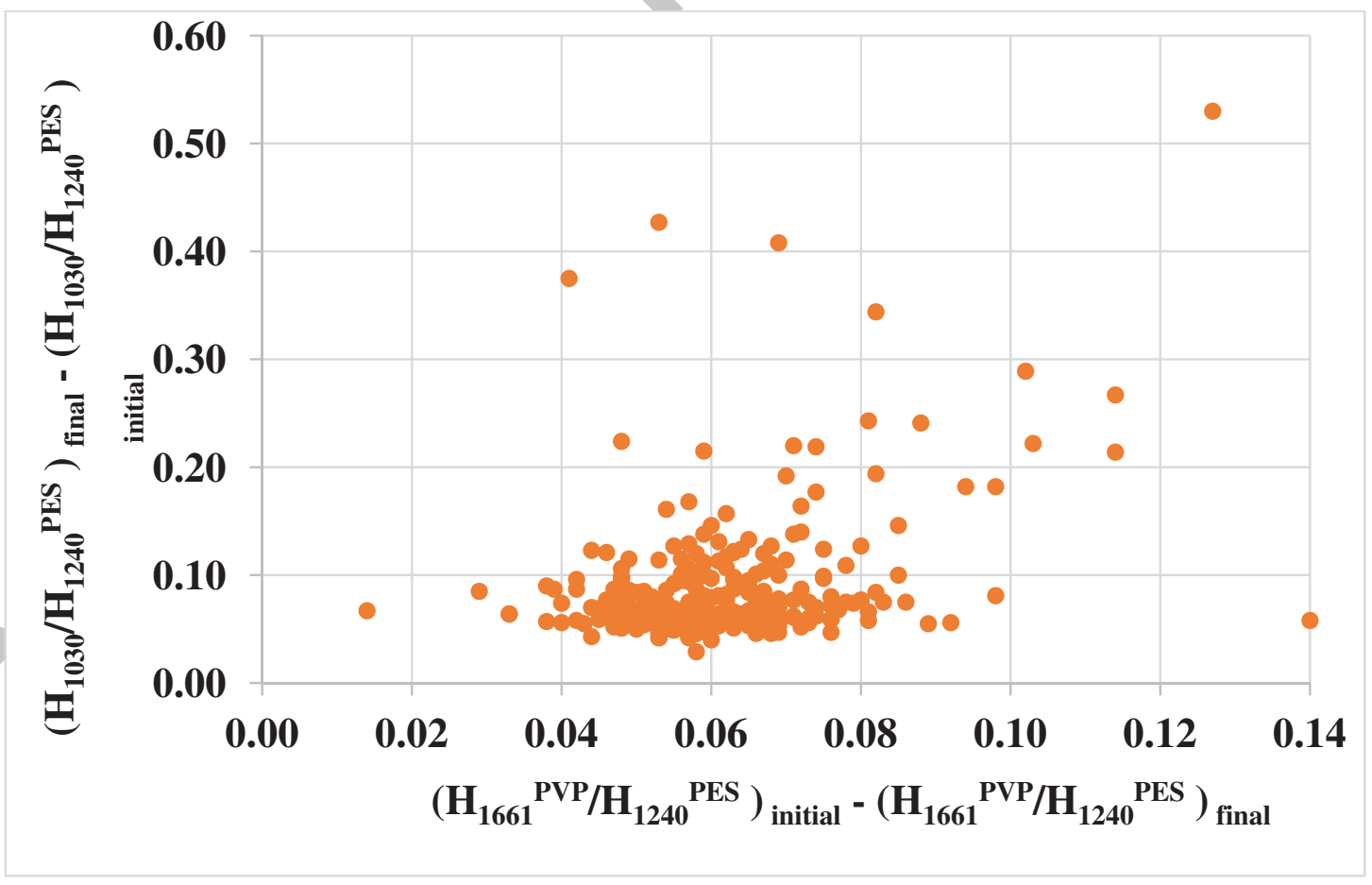


Figure A3-1: Increase of $1030 \mathrm{~cm}^{-1}$ band (according to FTIR-ATR, pristine membrane value is 0.04 ) versus decrease of PVP (according to FTIR-ATR, pristine membrane value is 0.14 ) (spectra acquired on 334 samples of CIP-3 spiral membrane)

Appendix 4: FTIR-ATR supporting data corresponding to Figures 10 (A4-1), 11 (A4-2), 12 (A4-3), 13 (A4-4).

\begin{tabular}{|c|c|c|c|c|c|c|c|c|}
\hline & F1C1 & & & & F1C2 & & & \\
\hline & Inlet & & A & & Inlet & & & Outlet \\
\hline & TMP(bar) & & & & 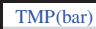 & & & \\
\hline & 5.0 & 4.5 & 3.9 & 3.4 & 5.0 & 4.5 & 3.9 & 3.4 \\
\hline $\mathrm{d}(\mathrm{mm})$ & \multicolumn{4}{|c|}{ permeate axis } & \multicolumn{4}{|c|}{ permeate axis } \\
\hline 45 & 68 & 71 & 57 & 55 & 59 & 54 & 57 & 64 \\
\hline 135 & 60 & 58 & 54 & 49 & 57 & 59 & 53 & 51 \\
\hline 225 & 58 & 56 & 58 & 53 & 54 & 58 & 53 & 52 \\
\hline 315 & 54 & 61 & 53 & 49 & 49 & 43 & 50 & 52 \\
\hline 405 & 52 & 51 & 53 & 49 & 48 & 46 & 50 & 47 \\
\hline 495 & 53 & 52 & 51 & 48 & 50 & 57 & 48 & 44 \\
\hline 585 & 51 & 50 & 49 & 53 & 62 & 46 & 42 & 47 \\
\hline 675 & 49 & 55 & 49 & 46 & 42 & 52 & 48 & 61 \\
\hline 765 & 47 & 49 & 48 & 46 & 47 & 43 & 42 & 33 \\
\hline 855 & 51 & 48 & 58 & 47 & 57 & 34 & 42 & 38 \\
\hline 945 & 37 & 37 & 42 & 39 & 25 & 25 & 26 & 26 \\
\hline
\end{tabular}



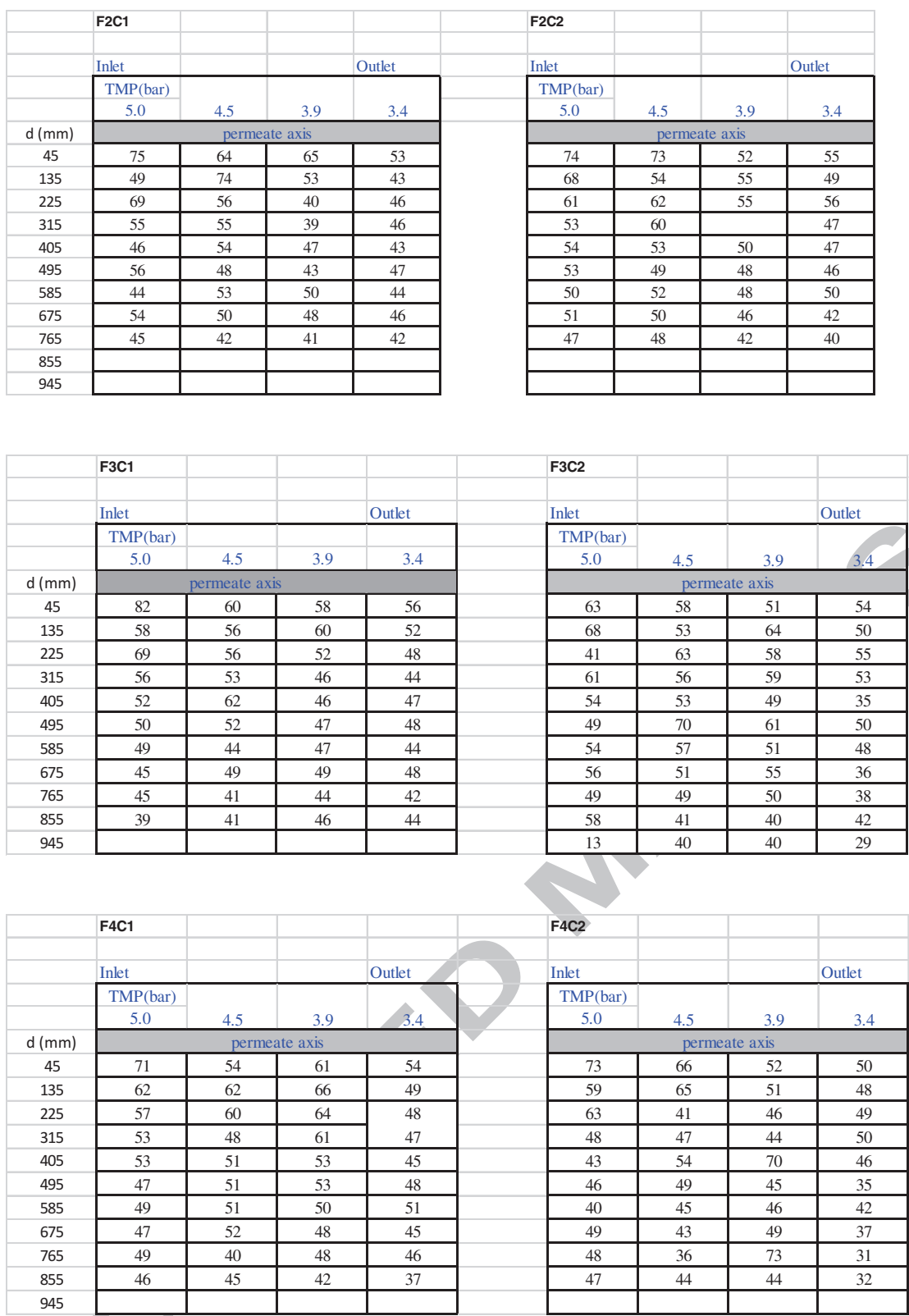

Figure A4-1. Mapping of the protein irreversible deposit in the spiral membrane determined from FTIR-ATR quantification (protein amount in $\mu \mathrm{g} . \mathrm{cm}^{-2}$ ) according to the location in the spiral membrane. The local TMP is calculated from the assumption of a linear pressure drop decrease. The membrane labels are defined on Figure 8. (white = not determined) 
F1C1

Inlet
\begin{tabular}{|c|c|c|c|}
\hline TMP(bar) & \multicolumn{2}{c|}{ Outlet } \\
\hline 5.0 & 4.5 & 3.9 & 3.4 \\
\hline \multicolumn{3}{|c|}{ permeate axis } \\
\hline 0.306 & 0.316 & 0.268 & 0.257 \\
\hline 0.269 & 0.274 & 0.252 & 0.248 \\
\hline 0.276 & 0.267 & 0.274 & 0.251 \\
\hline 0.248 & 0.259 & 0.255 & 0.235 \\
\hline 0.251 & 0.249 & 0.260 & 0.239 \\
\hline 0.261 & 0.256 & 0.255 & 0.232 \\
\hline 0.242 & 0.250 & 0.242 & 0.248 \\
\hline 0.240 & 0.250 & 0.239 & 0.235 \\
\hline 0.236 & 0.243 & 0.242 & 0.233 \\
\hline 0.253 & 0.237 & 0.258 & 0.234 \\
\hline 0.197 & 0.202 & 0.219 & 0.194 \\
\hline
\end{tabular}

\begin{tabular}{|c|c|c|c|}
\hline F1C2 & & & \\
\hline Inlet & & & Outlet \\
\hline TMP(bar) & & & \\
\hline 5.0 & 4.5 & 3.9 & 3.4 \\
\hline \multicolumn{4}{|c|}{ permeate axis } \\
\hline 0.283 & 0.272 & 0.242 & 0.261 \\
\hline 0.283 & 0.280 & 0.263 & 0.258 \\
\hline 0.268 & 0.279 & 0.268 & 0.244 \\
\hline 0.235 & 0.222 & 0.257 & 0.230 \\
\hline 0.237 & 0.221 & 0.254 & 0.244 \\
\hline 0.236 & 0.255 & 0.245 & 0.226 \\
\hline 0.234 & 0.242 & 0.206 & 0.241 \\
\hline 0.194 & 0.254 & 0.238 & 0.221 \\
\hline 0.215 & 0.219 & 0.237 & 0.173 \\
\hline 0.117 & 0.205 & 0.218 & 0.196 \\
\hline 0.139 & 0.150 & 0.158 & 0.150 \\
\hline
\end{tabular}




\begin{tabular}{|l|l|l|l|l|l|l|l|}
\hline \multicolumn{2}{|l|}{ F2C1 } & \multicolumn{2}{|l|}{ F2C2 } \\
\hline \\
\hline
\end{tabular}

\begin{tabular}{|c|c|c|c|c|}
\hline & $\mathrm{F} 3 \mathrm{C} 1$ & & & \\
\hline & Inlet & & & Outlet \\
\hline & TMP(bar) & & & \\
\hline & 5.0 & 4.5 & 3.9 & 3.4 \\
\hline$d(m m)$ & \multicolumn{4}{|c|}{ permeate axis } \\
\hline 45 & 0.335 & 0.302 & 0.261 & 0.270 \\
\hline 135 & 0.275 & 0.271 & 0.279 & 0.248 \\
\hline 225 & 0.285 & 0.275 & 0.268 & 0.248 \\
\hline 315 & 0.262 & 0.259 & 0.233 & 0.243 \\
\hline 405 & 0.257 & 0.268 & 0.235 & 0.231 \\
\hline 495 & 0.246 & 0.263 & 0.242 & 0.240 \\
\hline 585 & 0.243 & 0.231 & 0.244 & 0.233 \\
\hline 675 & 0.233 & 0.235 & 0.245 & \\
\hline 765 & 0.256 & 0.221 & 0.228 & 0.222 \\
\hline 855 & 0.218 & 0.220 & 0.234 & 0.229 \\
\hline 945 & & & & \\
\hline
\end{tabular}

\begin{tabular}{|c|c|c|c|}
\hline \\
\hline Inlet & & & Outlet \\
\hline \multicolumn{4}{|l|}{ TMP(bar) } \\
\hline 5.0 & 4.5 & 3.9 & 3.4 \\
\hline \multicolumn{4}{|c|}{ permeate axis } \\
\hline 0.272 & 0.270 & 0.240 & 0.267 \\
\hline 0.309 & 0.274 & 0.272 & 0.255 \\
\hline 0.262 & 0.281 & 0.280 & 0.261 \\
\hline 0.271 & 0.267 & 0.262 & 0.246 \\
\hline 0.259 & 0.269 & 0.247 & 0.230 \\
\hline 0.259 & 0.288 & 0.265 & 0.253 \\
\hline 0.256 & 0.257 & 0.259 & 0.248 \\
\hline 0.251 & 0.250 & 0.261 & 0.223 \\
\hline 0.242 & 0.247 & 0.254 & 0.227 \\
\hline 0.271 & 0.227 & 0.235 & 0.220 \\
\hline 0.138 & 0.205 & 0.217 & 0.172 \\
\hline
\end{tabular}

\begin{tabular}{|c|c|c|c|c|c|c|c|c|}
\hline & F4C1 & & & & F4C2 & & & \\
\hline & & & & & & & & \\
\hline & Inlet & & & Outlet & Inlet & & & Outlet \\
\hline & TMP(bar) & & & & TMP(bar) & & & \\
\hline & 5.0 & 4.5 & 3.9 & 3.4 & 5.0 & 4.5 & 3.9 & 3.4 \\
\hline $\mathrm{d}(\mathrm{mm})$ & \multicolumn{4}{|c|}{ permeate axis } & \multicolumn{4}{|c|}{ permeate axis } \\
\hline 45 & 0.316 & 0.265 & 0.283 & 0,239 & 0.274 & 0.290 & 0.255 & 0.251 \\
\hline 135 & 0.275 & 0.278 & 0.264 & 0.246 & 0.275 & 0.251 & 0.204 & 0.235 \\
\hline 225 & 0.266 & 0.273 & 0.297 & 0.239 & 0.289 & 0.213 & 0.235 & 0.251 \\
\hline 315 & 0.255 & 0.235 & 0.274 & 0.228 & 0.248 & 0.237 & 0.212 & 0.231 \\
\hline 405 & 0.257 & 0.257 & 0.240 & 0.231 & 0.213 & 0.266 & 0.272 & 0.221 \\
\hline 495 & 0.244 & 0.253 & 0.265 & 0.234 & 0.230 & 0.217 & 0.216 & $0.18 \mathrm{~s}$ \\
\hline 585 & 0.243 & 0.240 & 0.244 & 0.228 & 0.211 & 0.225 & 0.227 & $?$ \\
\hline 675 & 0.232 & 0.249 & 0.220 & 0.215 & 0.229 & 0.225 & 0.232 & 0.186 \\
\hline 765 & 0.256 & 0,206 & 0.231 & 0.243 & 0.250 & 0.205 & 0.244 & 0.192 \\
\hline 855 & 0.227 & 0.225 & 0.199 & 0.191 & 0.220 & 0.201 & 0.226 & 0.176 \\
\hline 945 & & 2 & & & & & & \\
\hline
\end{tabular}

Figure A4-2 Mapping of $\mathrm{H}_{1661}{ }^{\text {raw spectra }} / \mathrm{H}_{1240}{ }^{\text {PES }}$ obtained from FTIR-ATR according to the location in the spiral membrane. The local TMP is calculated from the assumption of a linear pressure drop decrease. The membrane labels are defined on Figure 8. (white = not determined) 


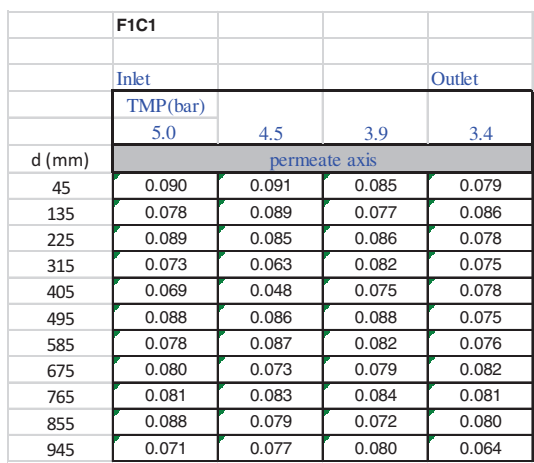

\begin{tabular}{|c|c|c|c|}
\hline F1C2 & & & \\
\hline Inlet & & & Outlet \\
\hline TMP(bar) & & & \\
\hline 5.0 & 4.5 & 3.9 & 3.4 \\
\hline & pern & axis & \\
\hline 0.092 & 0.098 & 0.059 & 0.058 \\
\hline 0.099 & 0.089 & 0.091 & 0.092 \\
\hline 0.093 & 0.092 & 0.094 & 0.073 \\
\hline 0.074 & 0.079 & 0.095 & 0.062 \\
\hline 0.081 & 0.069 & 0.092 & 0.090 \\
\hline 0.072 & 0.071 & 0.089 & 0.080 \\
\hline 0.037 & 0.085 & 0.067 & 0.087 \\
\hline 0.055 & 0.086 & 0.081 & 0.026 \\
\hline 0.060 & 0.077 & 0.096 & 0.060 \\
\hline 0 & 0.088 & 0.077 & 0.069 \\
\hline 0.051 & 0.059 & 0.064 & 0.058 \\
\hline
\end{tabular}

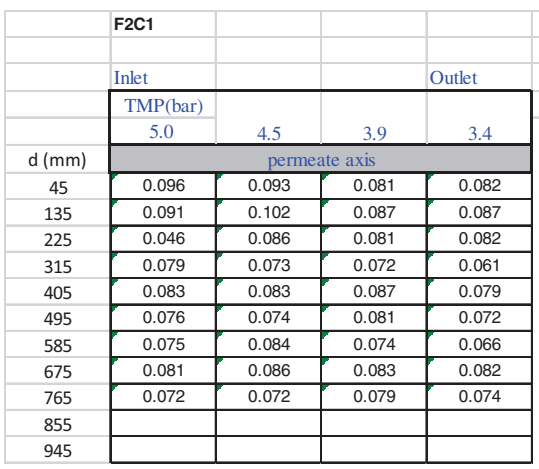

F2C2

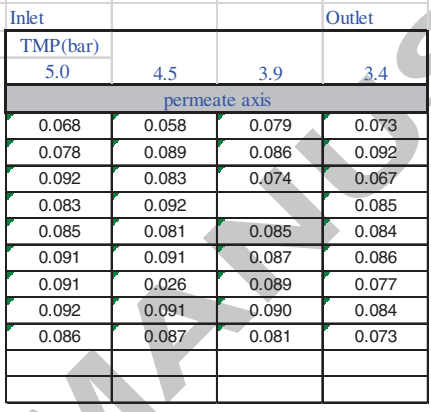

\begin{tabular}{|c|c|c|c|c|}
\hline & F3C1 & & & \\
\hline & Inlet & & & Outlet \\
\hline & TMP(bar) & & & \\
\hline & 5.0 & 4.5 & 3.9 & 3.4 \\
\hline $\mathrm{d}(\mathrm{mm})$ & \multicolumn{4}{|c|}{ permeate axis } \\
\hline 45 & 0.077 & 0.107 & 0.075 & 0.090 \\
\hline 135 & 0.089 & 0.088 & 0.086 & 0.078 \\
\hline 225 & 0.066 & 0.095 & 0.097 & 0.090 \\
\hline 315 & 0.082 & 0.088 & 0.080 & 0.096 \\
\hline 405 & 0.087 & 0.071 & 0.084 & 0.078 \\
\hline 495 & 0.082 & 0.093 & 0.086 & 0.083 \\
\hline 585 & 0.083 & 0.086 & 0.090 & 0.087 \\
\hline 675 & 0.085 & 0.075 & 0.084 & \\
\hline 765 & 0.107 & 0.085 & 0.083 & 0.081 \\
\hline 855 & 0.087 & 0.083 & 0.082 & 0.083 \\
\hline \multicolumn{5}{|l|}{945} \\
\hline & $\mathrm{F} 4 \mathrm{C} 1$ & & & \\
\hline & Inlet & & & Outlet \\
\hline & TMP(bar) & & & \\
\hline 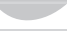 & 5.0 & 4.5 & 3.9 & 3.4 \\
\hline$d(\mathrm{~mm})$ & \multicolumn{4}{|c|}{ permeate axis } \\
\hline 45 & 0.092 & 0.088 & 0.089 & 0.064 \\
\hline 135 & 0.081 & 0.055 & 0.087 & 0.081 \\
\hline 225 & 0.082 & 0.092 & 0.083 & 0.083 \\
\hline 315 & 0.077 & 0.078 & 0.073 & 0.084 \\
\hline 405 & 0.090 & 0.069 & 0.083 & 0.090 \\
\hline 495 & 0.087 & 0.092 & 0.075 & 0.084 \\
\hline 585 & 0.074 & 0.080 & 0.062 & 0.078 \\
\hline 675 & 0.080 & 0.064 & 0.066 & 0.094 \\
\hline 765 & 0.071 & 0.074 & 0.091 & 0.077 \\
\hline 855 & 0.077 & 0.059 & 0.065 & 0.077 \\
\hline 945 & & & & \\
\hline
\end{tabular}

\begin{tabular}{|c|c|c|c|}
\hline \multicolumn{4}{|l|}{$\mathrm{F} 3 \mathrm{C} 2$} \\
\hline Inlet & & & Outlet \\
\hline \multicolumn{4}{|l|}{ TMP(bar) } \\
\hline 5.0 & 4.5 & 3.9 & 3.4 \\
\hline \multicolumn{4}{|c|}{ permeate axis } \\
\hline 0.070 & 0.082 & 0.073 & 0.092 \\
\hline 0.094 & 0.101 & 0.068 & 0.093 \\
\hline 0.126 & 0.081 & 0.094 & 0.083 \\
\hline 0.076 & 0.086 & 0.072 & 0.075 \\
\hline 0.085 & 0.098 & 0.087 & 0.111 \\
\hline 0.098 & 0.065 & 0.071 & 0.089 \\
\hline 0.082 & 0.072 & 0.093 & 0.092 \\
\hline 0.071 & 0.083 & 0.082 & 0.100 \\
\hline 0.081 & 0.086 & 0.091 & 0.100 \\
\hline 0.085 & 0.089 & 0.102 & 0.079 \\
\hline 0.082 & 0.071 & 0.082 & 0.069 \\
\hline
\end{tabular}

\begin{tabular}{|c|c|c|c|}
\hline F4C2 & & & \\
\hline Inlet & & & Outlet \\
\hline TMP(bar) & & & \\
\hline 5.0 & 4.5 & 3.9 & 3.4 \\
\hline & perr & axis & \\
\hline 0.042 & 0.080 & 0.086 & 0.086 \\
\hline 0.086 & 0.042 & 0.038 & 0.078 \\
\hline 0.087 & 0.075 & 0.082 & 0.090 \\
\hline 0.090 & 0.081 & 0.065 & 0.068 \\
\hline 0.071 & 0.092 & 0.052 & 0.070 \\
\hline 0.080 & 0.057 & 0.066 & 0.069 \\
\hline 0.078 & 0.077 & 0.075 & \\
\hline 0.068 & 0.081 & 0.071 & 0.060 \\
\hline 0.092 & 0.083 & 0.013 & 0.085 \\
\hline 0.067 & 0.054 & 0.080 & 0.064 \\
\hline
\end{tabular}


Figure A4-3. Mapping of $\mathrm{H}_{1661}{ }^{\mathrm{PVP}} / \mathrm{H}_{1240}{ }^{\mathrm{PES}}$ obtained from equation 3 according to the location in the spiral membrane. The local TMP is calculated from the assumption of a linear pressure drop decrease. The membrane labels are defined on Figure 8. (white $=$ not determined) 


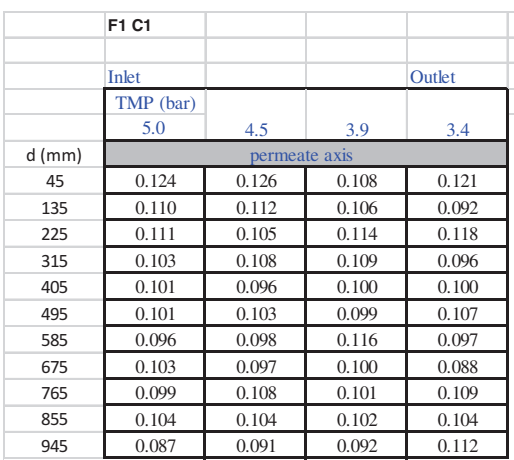

\begin{tabular}{|c|c|c|c|}
\hline $\mathrm{F} 1 \mathrm{C} 2$ & & & \\
\hline Inlet & & & Outlet \\
\hline TMP (bar) & & & \\
\hline 5.0 & 4.5 & 3.9 & 3.4 \\
\hline & perm & & \\
\hline 0.264 & 0.136 & 0.283 & 0.234 \\
\hline 0.415 & 0.125 & 0.155 & 0.117 \\
\hline 0.127 & 0.138 & 0.113 & 0.144 \\
\hline 0.141 & 0.171 & 0.099 & 0.149 \\
\hline 0.121 & 0.178 & 0.098 & 0.092 \\
\hline 0.167 & 0.448 & 0.094 & 0.119 \\
\hline 0.262 & 0.132 & 0.115 & 0.088 \\
\hline 0.140 & 0.104 & 0.255 & 0.307 \\
\hline 0.167 & 0.162 & 0.110 & 0.117 \\
\hline 0.098 & 0.120 & 0.093 & 0.117 \\
\hline 0.095 & 0.098 & 0.087 & 0.124 \\
\hline
\end{tabular}
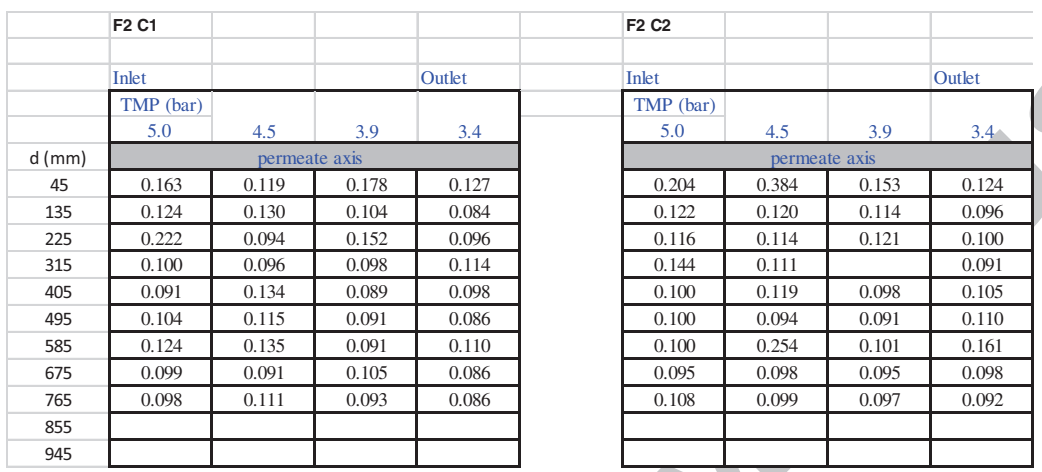

\begin{tabular}{|c|c|c|c|c|}
\hline & F3 C1 & & & \\
\hline & Inlet & & & Outlet \\
\hline & TMP (bar) & & & \\
\hline & 5.0 & 4.5 & 3.9 & 3.4 \\
\hline $\mathrm{d}(\mathrm{mm})$ & \multicolumn{4}{|c|}{ permeate axis } \\
\hline 45 & 0.127 & 0.104 & 0.135 & 0.106 \\
\hline 135 & 0.096 & 0.106 & 0.099 & 0.117 \\
\hline 225 & 0.217 & 0.109 & 0.095 & 0.098 \\
\hline 315 & 0.111 & 0.099 & 0.080 & 0.083 \\
\hline 405 & 0.114 & 0.103 & 0.101 & 0.102 \\
\hline 495 & 0.092 & 0.092 & 0.090 & 0.091 \\
\hline 585 & 0.094 & 0.095 & 0.090 & 0.087 \\
\hline 675 & 0.090 & 0.098 & 0.093 & \\
\hline 765 & 0.104 & 0.089 & 0.085 & 0.094 \\
\hline 855 & 0.082 & 0.082 & 0.090 & 0.084 \\
\hline \multicolumn{5}{|l|}{945} \\
\hline \multicolumn{5}{|c|}{ F4 C1 } \\
\hline & Inlet & & & Outlet \\
\hline & TMP (bar) & & & \\
\hline & 5.0 & 4.5 & 3.9 & 3.4 \\
\hline$d(m m)$ & \multicolumn{4}{|c|}{ permeate axis } \\
\hline 45 & 0.131 & 0.116 & 0.122 & 0.120 \\
\hline 135 & 0.140 & 0.186 & 0.467 & 0.097 \\
\hline 225 & 0.160 & 0.137 & 0.169 & 0.101 \\
\hline 315 & 0.128 & 0.147 & 0.160 & 0.141 \\
\hline 405 & 0.106 & 0.101 & 0.146 & 0.096 \\
\hline 495 & 0.082 & 0.110 & 0.093 & 0.155 \\
\hline 585 & 0.102 & 0.119 & 0.115 & 0.197 \\
\hline 675 & 0.103 & 0.099 & 0.259 & 0.161 \\
\hline 765 & 0.093 & 0.096 & 0.111 & 0.092 \\
\hline 855 & 0.098 & 0.106 & 0.139 & 0.138 \\
\hline 945 & & & & \\
\hline
\end{tabular}

\begin{tabular}{|c|c|c|c|}
\hline $\mathrm{F} 3 \mathrm{C} 2$ & & & \\
\hline Inlet & & & Outlet \\
\hline TMP (bar) & & & \\
\hline 5.0 & 4.5 & 3.9 & 3.4 \\
\hline & perm & & \\
\hline 0.232 & 0.136 & 0.125 & 0.146 \\
\hline 0.117 & 0.127 & 0.127 & 0.105 \\
\hline 0.107 & 0.141 & 0.101 & 0.115 \\
\hline 0.164 & 0.201 & 0.150 & 0.098 \\
\hline 0.109 & 0.127 & 0.116 & 0.125 \\
\hline 0.098 & 0.137 & 0.112 & 0.098 \\
\hline 0.098 & 0.148 & 0.094 & 0.091 \\
\hline 0.110 & 0.208 & 0.119 & 0.096 \\
\hline 0.107 & 0.109 & 0.094 & 0.114 \\
\hline 0.101 & 0.105 & 0.097 & 0.097 \\
\hline 0.069 & 0.118 & 0.086 & 0.102 \\
\hline
\end{tabular}

\begin{tabular}{|c|c|c|c|}
\hline F4 C2 & & & \\
\hline Inlet & & & Outlet \\
\hline TMP (bar) & \multirow[b]{2}{*}{4.5} & \multirow[b]{2}{*}{3.9} & \multirow[b]{2}{*}{3.4} \\
\hline 5.0 & & & \\
\hline \multicolumn{4}{|c|}{ permeate axis } \\
\hline 0.222 & 0.137 & 0.110 & 0.111 \\
\hline 0.126 & 0.121 & 0.329 & 0.157 \\
\hline 0.154 & 0.173 & 0.103 & 0.099 \\
\hline 0.102 & 0.101 & 0.164 & 0.180 \\
\hline 0.096 & 0.139 & 0.281 & 0.154 \\
\hline 0.186 & 0.115 & 0.102 & 0.260 \\
\hline 0.116 & 0.136 & 0.130 & \\
\hline 0.092 & 0.119 & 0.140 & 0.116 \\
\hline 0.091 & 0.083 & 0.570 & 0.167 \\
\hline 0.096 & 0.115 & 0.096 & 0.099 \\
\hline
\end{tabular}


Figure A4-4. Mapping of $\mathrm{H}_{1030} / \mathrm{H}_{1240}$ PES according to the location in the spiral membrane. The local TMP is calculated from the assumption of a linear pressure drop decrease. The membrane labels are defined on Figure 8. (white $=$ not determined).

\section{Tables}

Table 1. Conditions of membrane accelerated ageing, FTIR-ATR characteristics and protein amount further adsorbed on (aged) membrane surface.

\begin{tabular}{|c|c|c|c|}
\hline & $\begin{array}{l}\text { Ageing time (min) } \\
\text { (micro-waves) }\end{array}$ & $\begin{array}{c}\text { FTIR-ATR* }^{*} \\
\mathrm{H}_{1661}{ }^{\mathrm{PVP}} / \mathrm{H}_{1240}{ }^{\mathrm{PES}}\end{array}$ & $\begin{array}{l}\text { Range of protein deposit on } \\
\text { membrane surface }\left(\mu \mathrm{g} . \mathrm{cm}^{-2}\right)\end{array}$ \\
\hline Pristine membrane & 0 & $\begin{array}{c}0.14 \pm 0.01 \\
(n=6)\end{array}$ & $0-208$ \\
\hline Ageing by $\mathrm{NaOCl}$ & & $\begin{array}{c}0.10 \pm 0.01 \\
\quad(n=6)\end{array}$ & $0-76$ \\
\hline Ageing by $\mathrm{NaOCl}$ & 480 & $\begin{array}{c}0.07 \pm 0.01 \\
\quad(n=6)\end{array}$ & $0-82$ \\
\hline
\end{tabular}


Table 2. Description of the three FTIR-ATR spectrometers used in this study

\begin{tabular}{|c|c|c|c|}
\hline & Spectrometer 1 & Spectrometer 2 & Spectrometer 3 \\
\hline & Paragon 1000 & FT/IR-4100 & Spectrum 100 \\
\hline & Perkin-Elmer & Jasco & Perkin Elmer \\
\hline \multirow{3}{*}{$\begin{array}{l}\text { ATR } \\
\text { accessory }\end{array}$} & ZnSe crystal & ZnSe crystal & Diamond crystal \\
\hline & incidence angle: $45^{\circ}$ & incidence angle: $45^{\circ}$ & incidence angle: $45^{\circ}$ \\
\hline & 12 reflections & 1 reflection & 1 reflection \\
\hline $\begin{array}{l}\text { Crystal } \\
\text { dimension }\end{array}$ & $2 \mathrm{~cm} \times 5 \mathrm{~cm}$ & $1.8 \mathrm{~mm}$ diameter & $2 \mathrm{~mm}$ diameter \\
\hline Software & $\begin{array}{l}\text { Spectrum for windows } \\
5\end{array}$ & Spectra Manager II & Spectrum for windows 6 \\
\hline \multirow{5}{*}{$\begin{array}{l}\text { Acquisition } \\
\text { conditions }\end{array}$} & spectral domain : & spectral domain : & spectral domain : \\
\hline & $4000-600 \mathrm{~cm}^{-1}$ & $3700-600 \mathrm{~cm}^{-1}$ & $4000-600 \mathrm{~cm}^{-1}$ \\
\hline & resolution : $2 \mathrm{~cm}^{-1}$ & resolution : $2 \mathrm{~cm}^{-1}$ & resolution : $2 \mathrm{~cm}^{-1}$ \\
\hline & 20 scans & 128 scans & 20 scans \\
\hline & background : air & background : air & background : air \\
\hline
\end{tabular}


Table $4-\mathrm{H}_{\mathrm{i}} / \mathrm{H}_{1240}{ }^{\text {PES }}$ ratio from FTIR-ATR before and after fouling of the $210 \mathrm{~min}$ microwaves aged membrane by proteins.

\begin{tabular}{|l|l|l|l|l|}
\hline $\begin{array}{l}\text { Protein } \\
\text { concentration } \\
\text { solution }\left(\mathrm{g} . \mathrm{L}^{-1}\right)\end{array}$ & $\begin{array}{l}\mathrm{H}_{1661}{ }^{\mathrm{PVP}} / \mathrm{H}_{1240}{ }^{\mathrm{PES}} \\
\text { (not fouled) }\end{array}$ & $\begin{array}{l}\mathrm{H}_{1661}{ }^{\text {raw }} \\
\text { spectra } / \mathrm{H}_{1240}{ }^{\mathrm{PES}} \\
\text { (fouled) }\end{array}$ & $\begin{array}{l}\mathrm{H}_{1539}{ }^{\text {protein }} \\
\mathrm{II} / \mathrm{H}_{1240}{ }^{\mathrm{PES}} \text { (fouled) }\end{array}$ & $\begin{array}{l}\mathrm{H}_{1661}{ }^{\text {protein }} \\
\mathrm{I} / \mathrm{H}_{1240}{ }^{\mathrm{PES}} \text { (from Eq. } \\
3 \text { ) }\end{array}$ \\
\hline 0 & 0.116 & & & 0.065 \\
\hline 5 & 0.084 & 0.149 & 0.084 & 0.075 \\
\hline 10 & 0.093 & 0.167 & 0.094 & 0.105 \\
\hline 20 & 0.093 & 0.198 & 0.126 & 0.189 \\
\hline 30 & 0.100 & 0.290 & 0.213 & 0.248 \\
\hline 50 & 0.099 & 0.348 & 0.275 & \\
\hline
\end{tabular}

Table $5-\mathrm{H}_{\mathrm{i}} / \mathrm{H}_{1240}{ }^{\text {PES }}$ ratio from FTIR-ATR before and after fouling of the 480 min microwaves aged membrane by proteins

\begin{tabular}{|c|c|c|c|c|}
\hline $\begin{array}{l}\text { Protein } \\
\text { concentration in } \\
\text { solution }\left(\mathrm{g} \cdot \mathrm{L}^{-1}\right)\end{array}$ & $\begin{array}{l}\mathrm{H}_{1661}{ }^{\mathrm{PVP}} / \mathrm{H}_{1240}{ }^{\mathrm{PES}} \\
\text { (not fouled) }\end{array}$ & $\begin{array}{l}\mathrm{H}_{1661}{ }^{\text {raw }} \\
\text { spectra/ } / \mathrm{H}_{1240} \text { PES } \\
\text { (fouled) }\end{array}$ & $\begin{array}{l}\mathrm{H}_{1539}{ }^{\text {protein }} \text { amide } \\
{ }^{\mathrm{II}} / \mathrm{H}_{1240}{ }^{\text {PES }} \text { (fouled) }\end{array}$ & $\begin{array}{l}\mathrm{H}_{1661}{ }^{\text {protein }} \text { amide } \\
{ }^{\mathrm{I}} / \mathrm{H}_{1240}{ }^{\text {PES }} \text { (from Eq. } \\
\text { 3) }\end{array}$ \\
\hline 0 & 0.073 & & & \\
\hline 5 & 0.058 & 0.113 & 0.060 & 0.055 \\
\hline 10 & 0.060 & 0.154 & 0.098 & 0.094 \\
\hline 20 & 0.066 & 0.208 & 0.144 & 0.141 \\
\hline 30 & 0.076 & 0.252 & 0.177 & 0.176 \\
\hline 50 & 0.062 & 0.361 & 0.297 & 0.299 \\
\hline
\end{tabular}




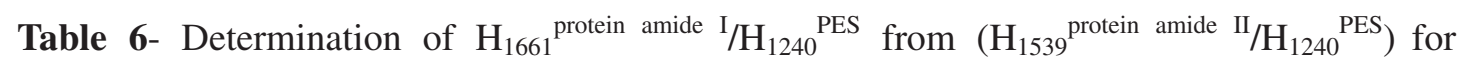
different membranes

\begin{tabular}{|c|c|c|c|c|}
\hline$\left(\mathrm{H}_{1661}{ }^{\mathrm{PVP}} / \mathrm{H}_{1240}{ }^{\mathrm{PES}}\right)$ & $\begin{array}{l}\mathrm{H}_{1661}{ }^{\text {protein }}{ }^{\text {amide }} \\
\mathrm{I} / \mathrm{H}_{1240}{ }^{\text {PES }}= \\
\left(\mathrm{H}_{1539}{ }^{\text {protein }}\right. \\
\left.{ }^{\mathrm{II}} / \mathrm{H}_{1240}{ }^{\mathrm{PES}}\right)(\mathrm{y}=\mathrm{a} \mathrm{x})\end{array}$ & Number of values & $\begin{array}{l}\text { Correlation } \\
\text { coefficient } \mathrm{R}^{2}\end{array}$ & $\begin{array}{l}\text { Range of protein } \\
\text { amount } \\
\text { membrane surface } \\
\left(\mu \mathrm{g} . \mathrm{cm}^{-2}\right)\end{array}$ \\
\hline 0.14 (Pristine) & $y=0.85 x$ & 6 & 0.999 & $0-208$ \\
\hline $0.10(210 \mathrm{~min}$ aged $)$ & $y=0.88 x$ & 6 & 0.975 & $0-76$ \\
\hline 0.07 (480 min aged) & $y=0.99 x$ & 6 & 0.996 & $0-82$ \\
\hline Average & $y=0.87 x$ & 18 & 0.991 & $0-76(208)$ \\
\hline
\end{tabular}


Figures

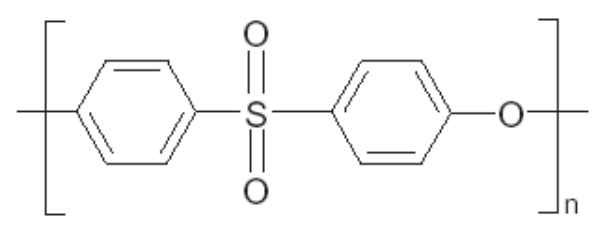

(a) Polyethersulfone

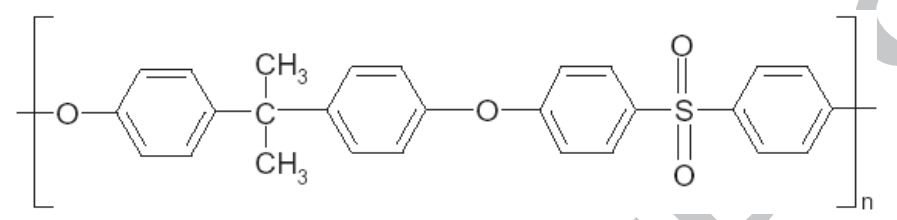

(b) Polysulfone

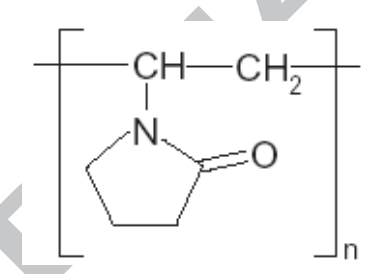

(c) Polyvinylpyrrolidone

Figure 1: Some polymers constituting active layer of membranes 


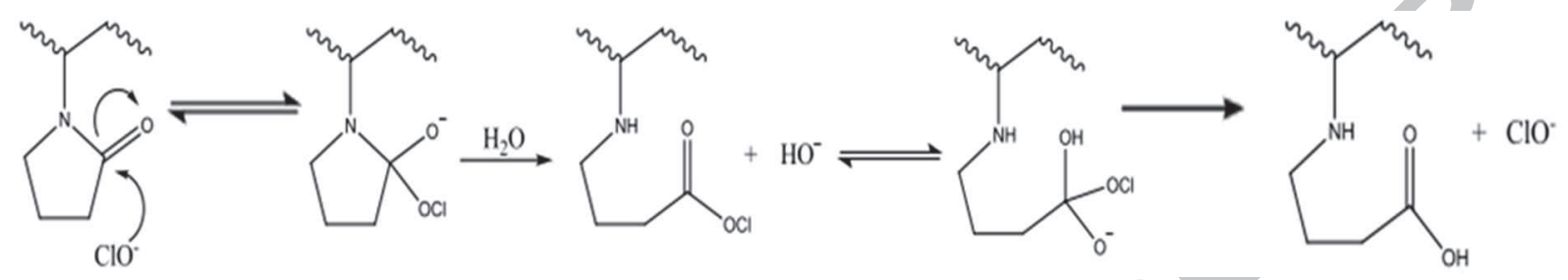

Figure 2: Opening of the PVP ring opening by hypochlorite in alkaline conditions according to Wienk et al. [22] 


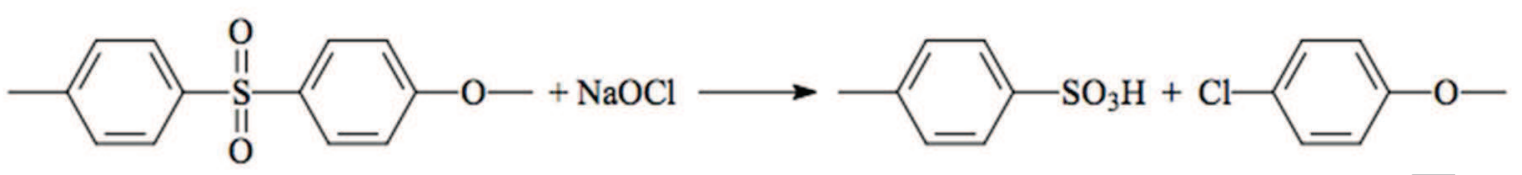

(a)

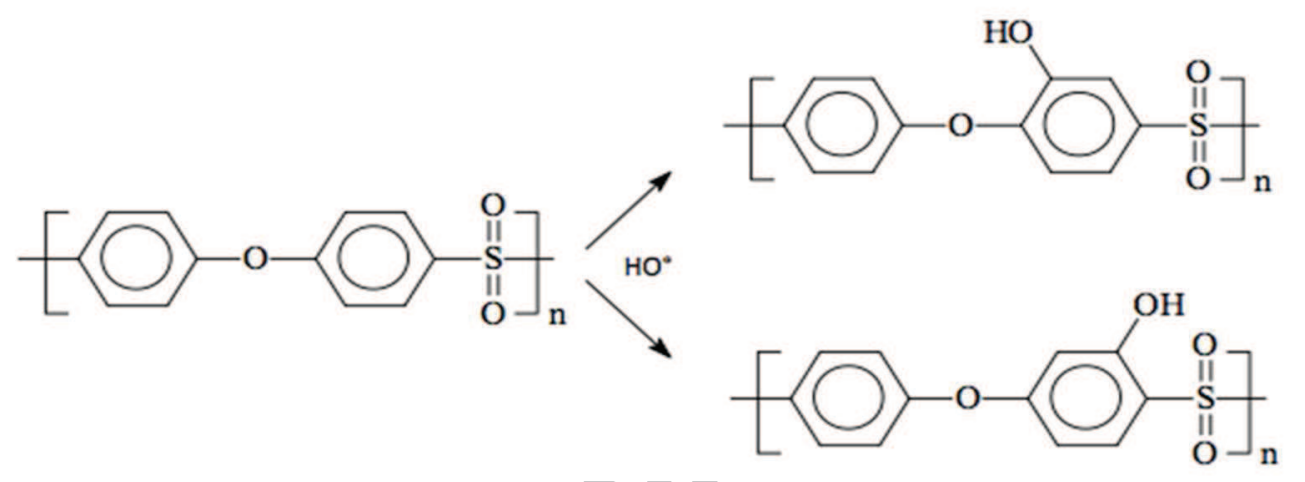

(b)

Figure 3: Evolution of PES skeleton by formation of - (a) sulfonic acid group according to [14] and (b) phenol group ( $\mathrm{OH}$ on the phenyl ring) according to [18] 


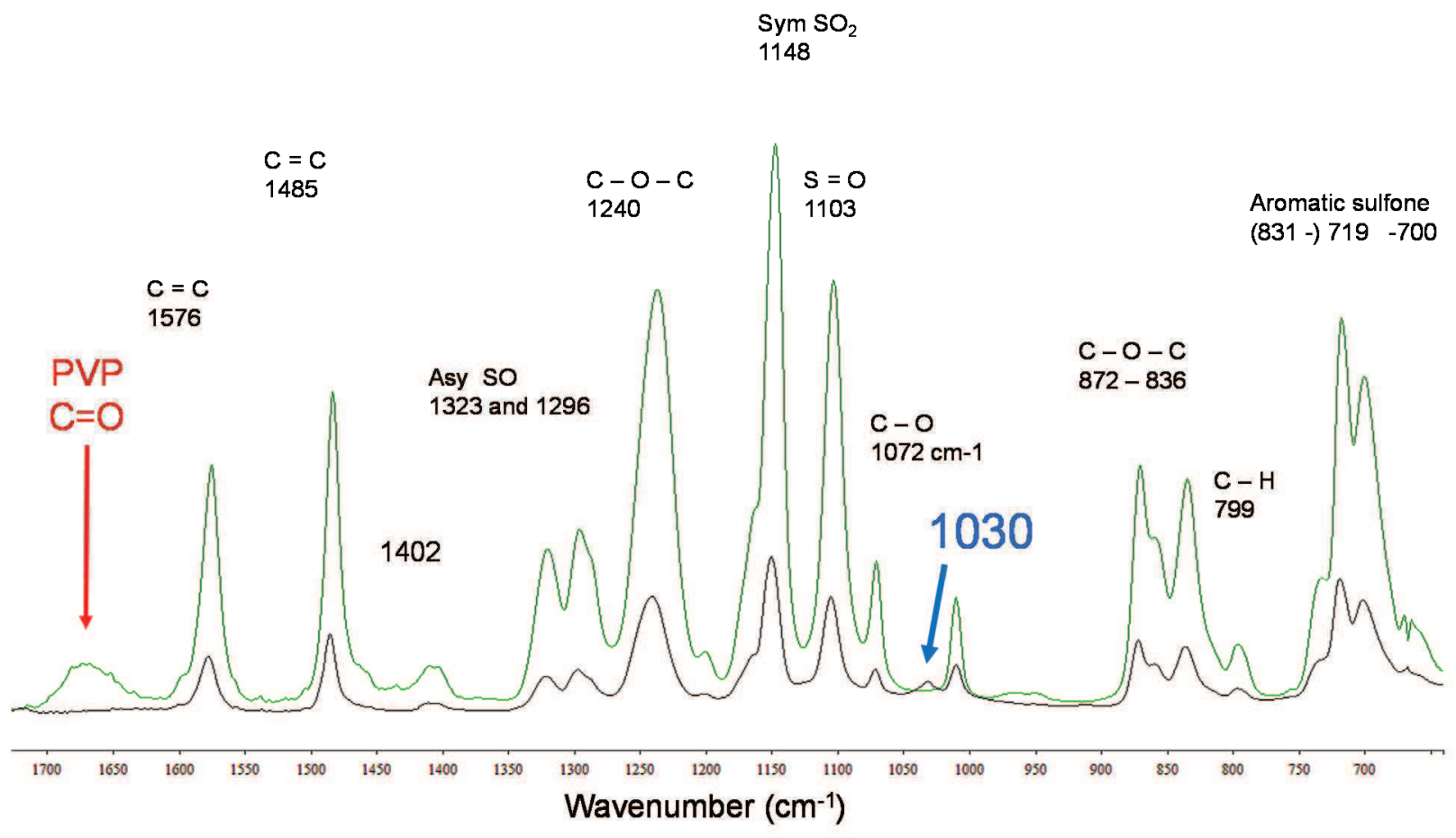

Figure 4: FTIR-ATR raw spectra of a pristine PES/PVP membrane (HFK-131, Koch) in green and with smaller intensity of an industrial membrane at the end of its service life (membrane $U$ ) 

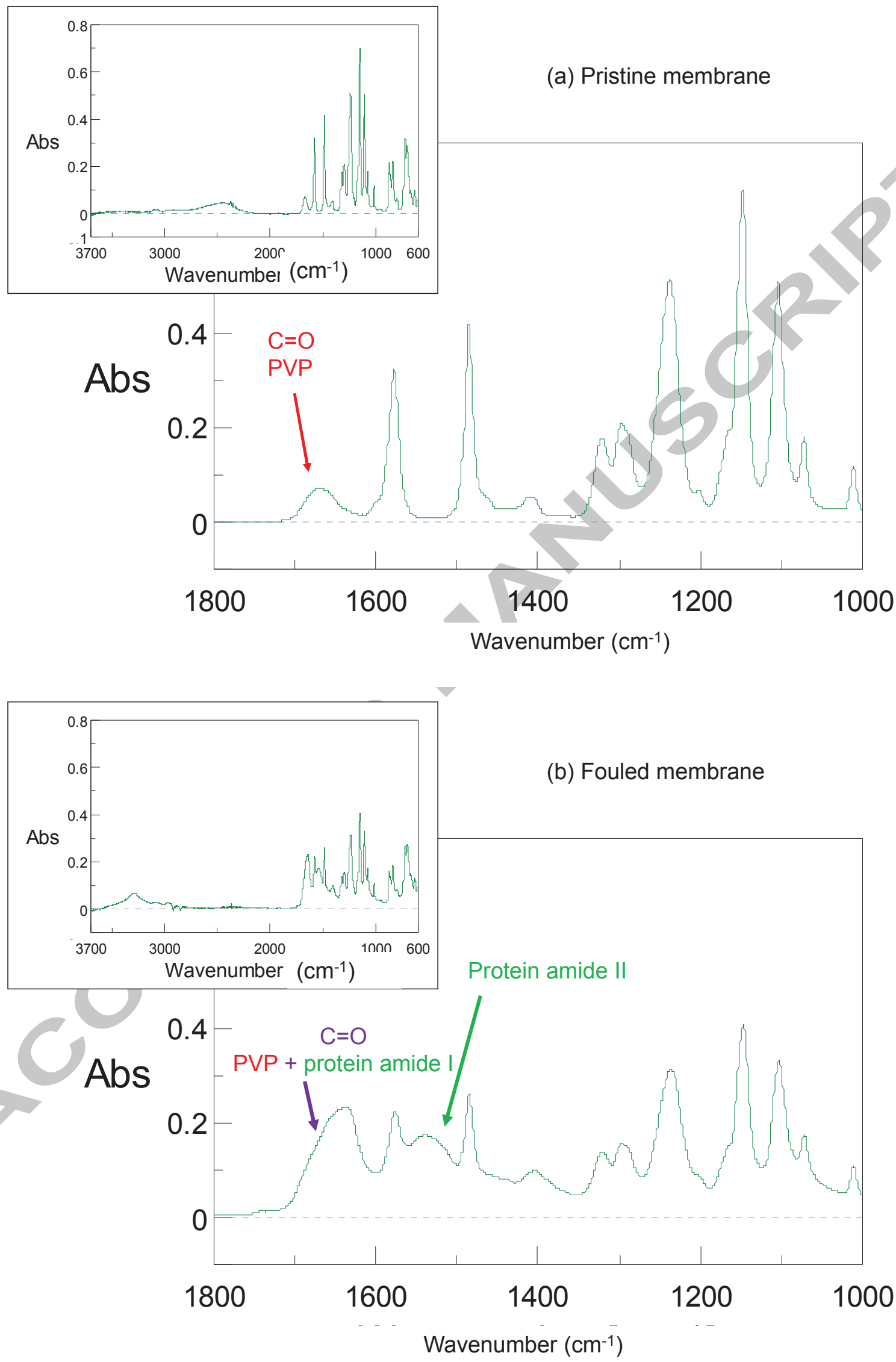

Figure 5: Raw spectra of a PES/PVP membrane - (a) without or (b) with protein fouling 


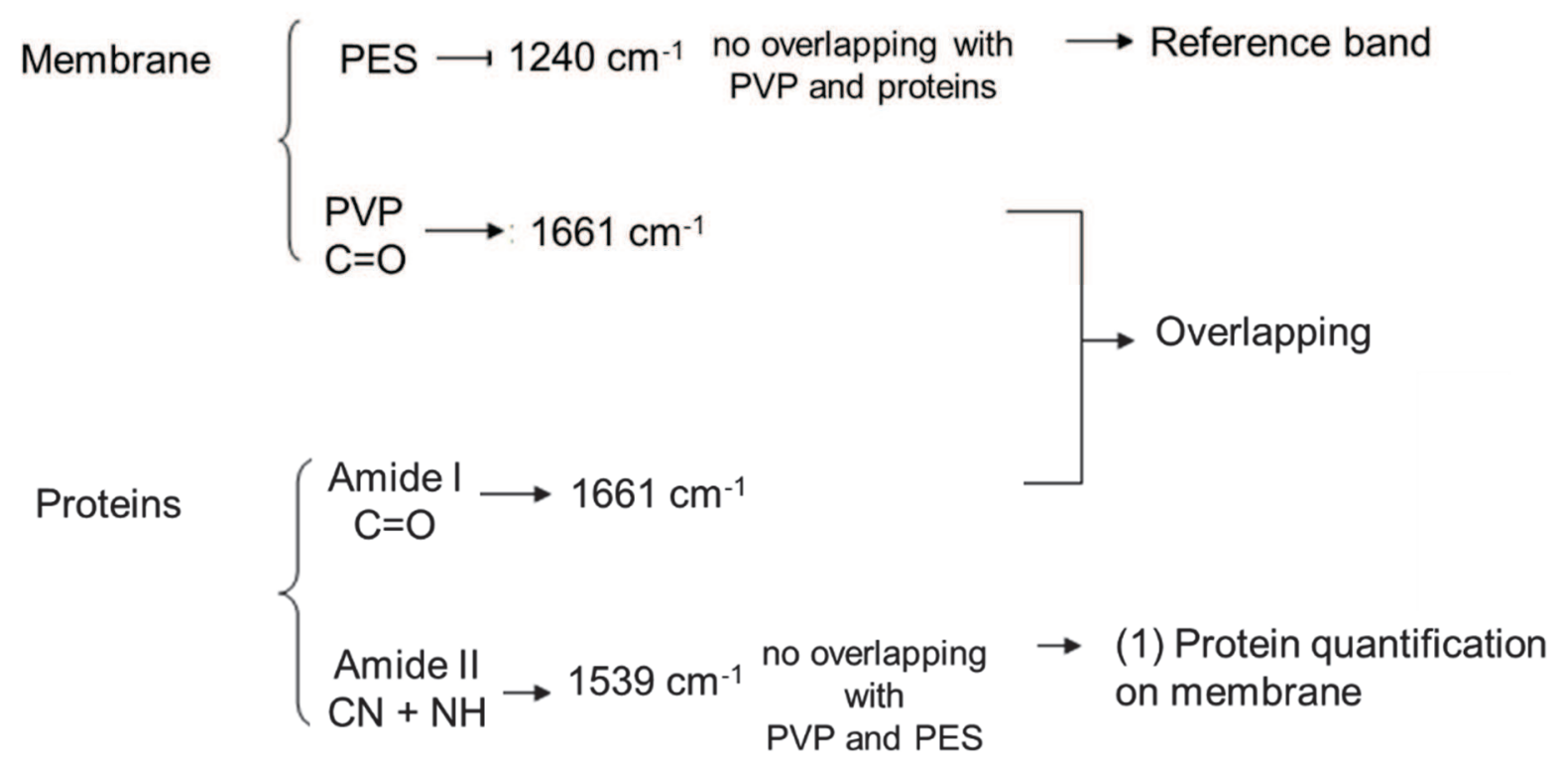

(2) Evaluation of Amide I intensity

Figure 6: Summary of the analytical difficulty to overcome and of the proposed approach 


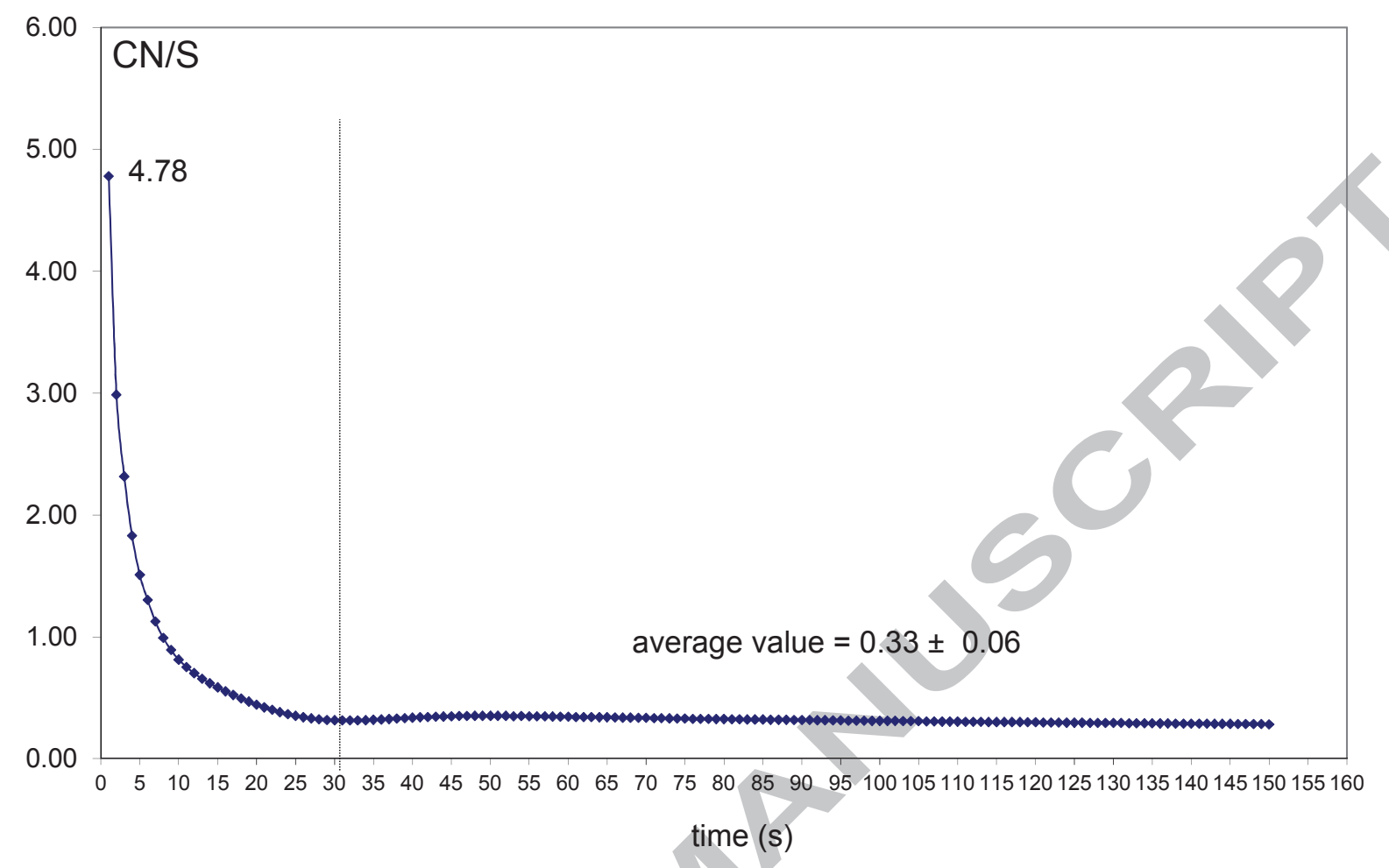

Figure 7: NanoSIMS analysis of the pristine HFK-131 membrane highlighting presence of nitrogen. $Y$-axis gives the atomic ratio of organic nitrogen to sulfur considering that $N$ comes from PVP and S from PES. The longer is the atom ablation time on the x-axis the deeper is the analysis in the membrane. There is more PVP on the surface of the membrane but it never disappears 


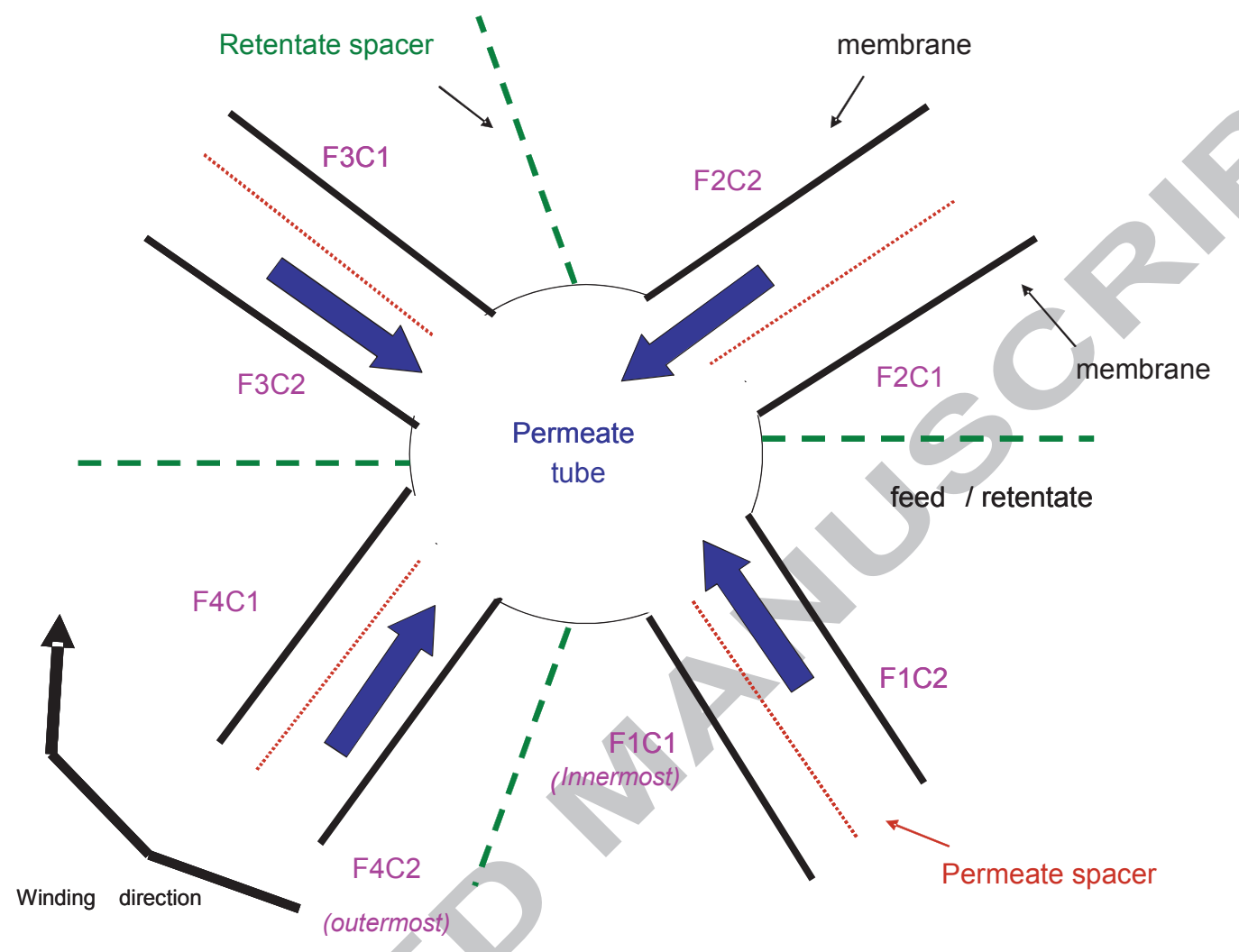

Figure 8. Scheme of the spiral membrane with 4 double sheets highlighting the different channels in which are inserted retentate or permeate spacer, respectively. Each membrane is labelled according to the same nomenclature as those used for the quantification of protein amount for the autopsied membrane (see results). F1C1 is the innermost membrane sheet whereas F4C2 is the outermost one. 


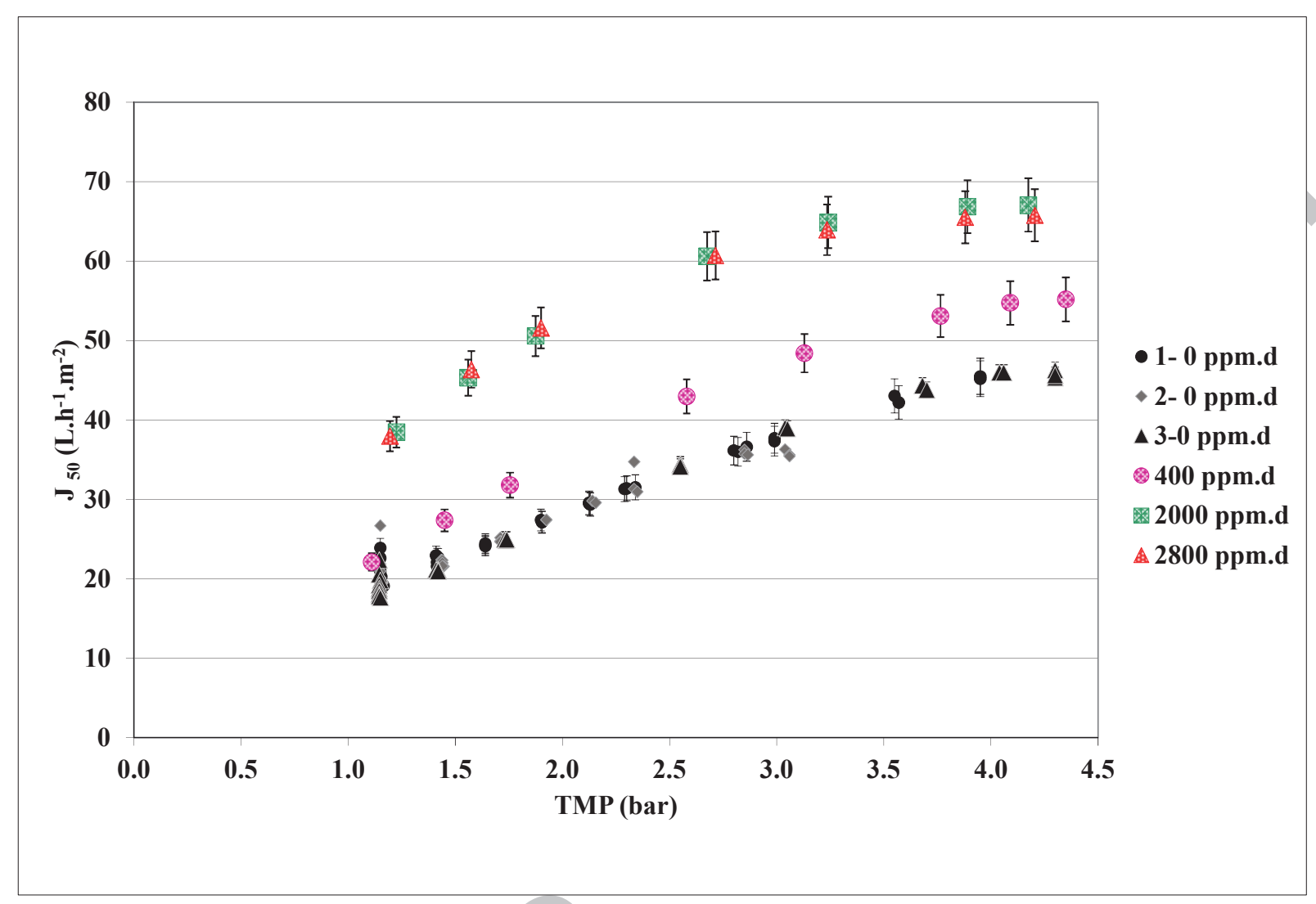

Figure 9: Evolution of flux in skim milk according to $\mathrm{NaOCl}$ dose received by the spiral membrane 

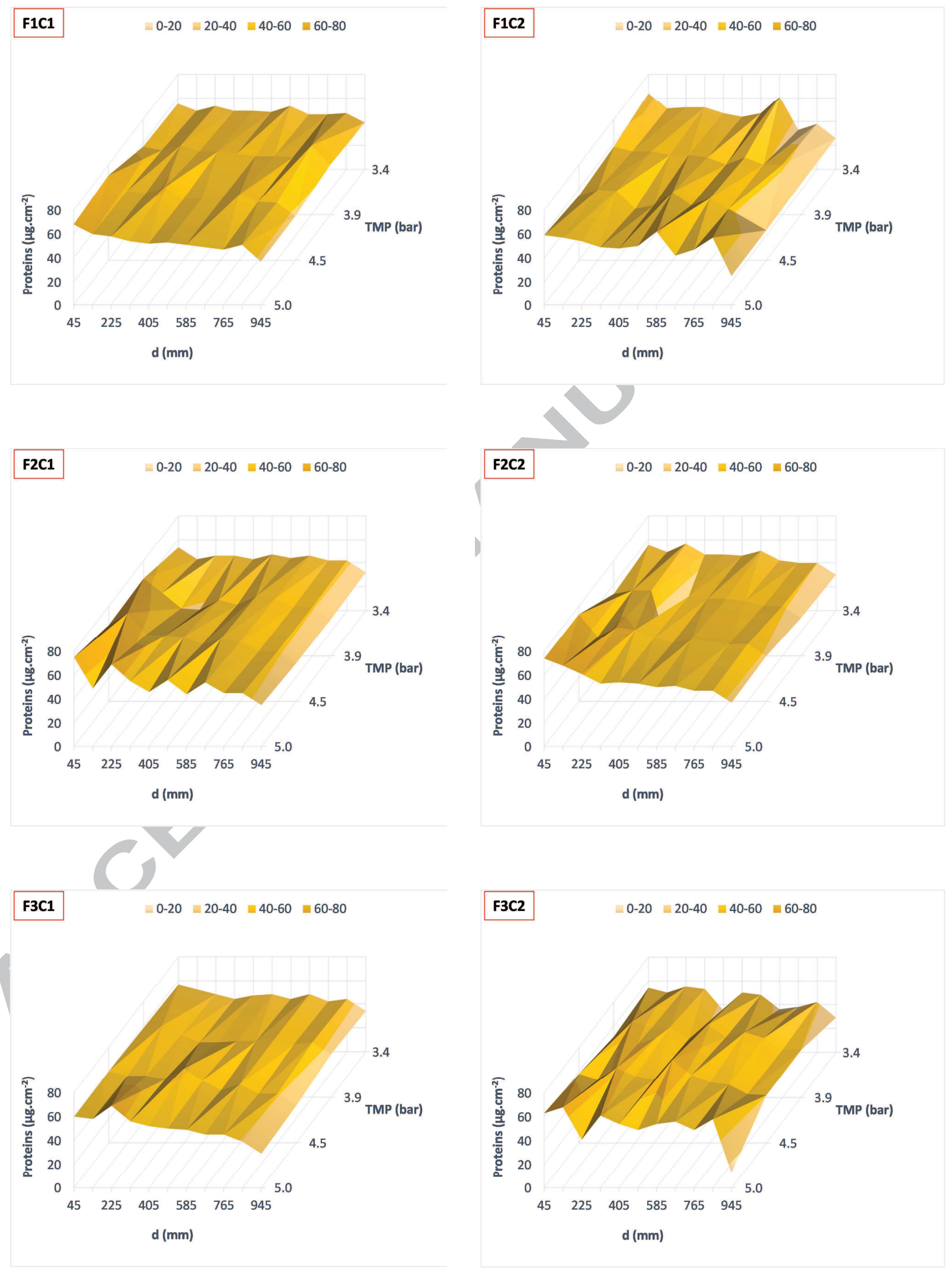

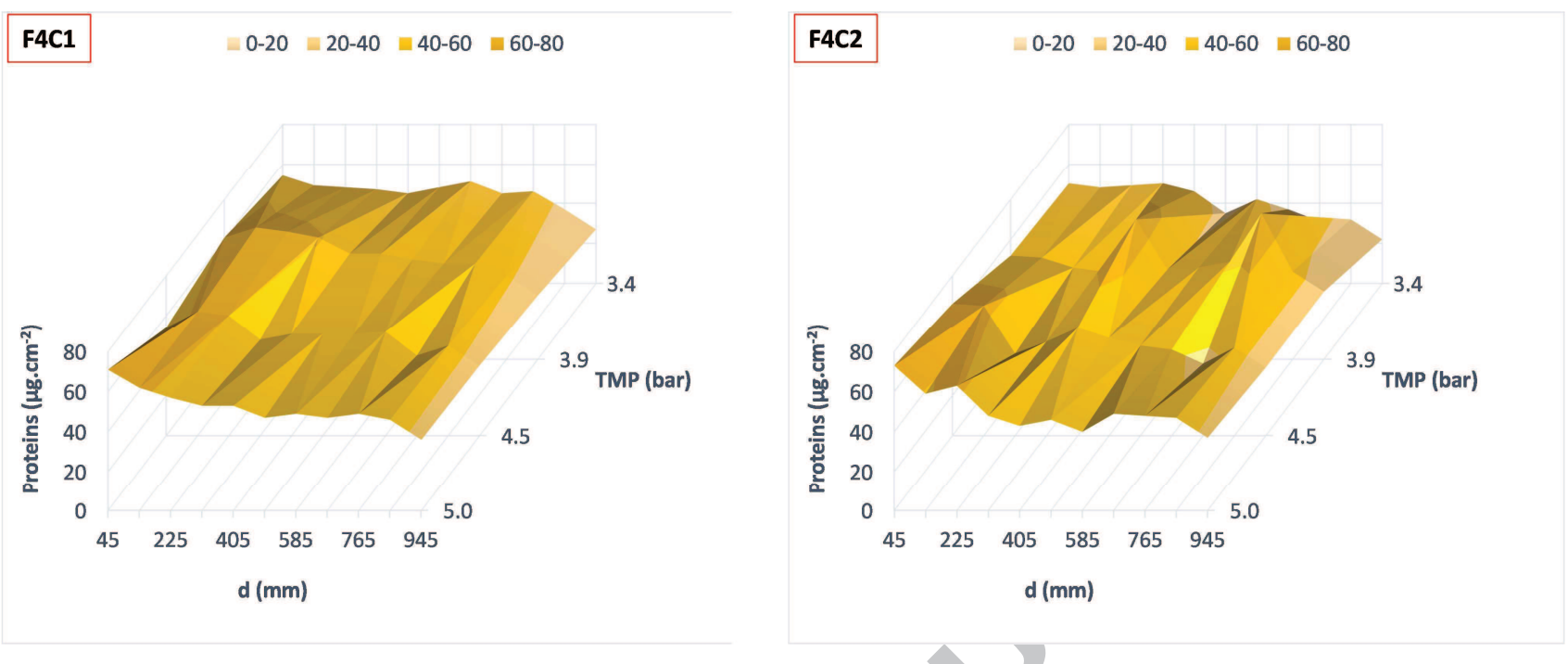

Figure 10. Mapping of the protein irreversible deposit in the spiral membrane determined from FTIR-ATR quantification (protein amount in $\mu \mathrm{g} . \mathrm{cm}^{-2}$ ) according to the location in the spiral membrane. The local TMP is calculated from the assumption of a linear pressure drop decrease. The membrane labels are defined on Figure 8. TMP decreases from the inlet to the outlet of the spiral membrane. $\mathrm{d}$ is the distance from the permeate axis $(\mathrm{d}=0)$ for a membrane sheet. 


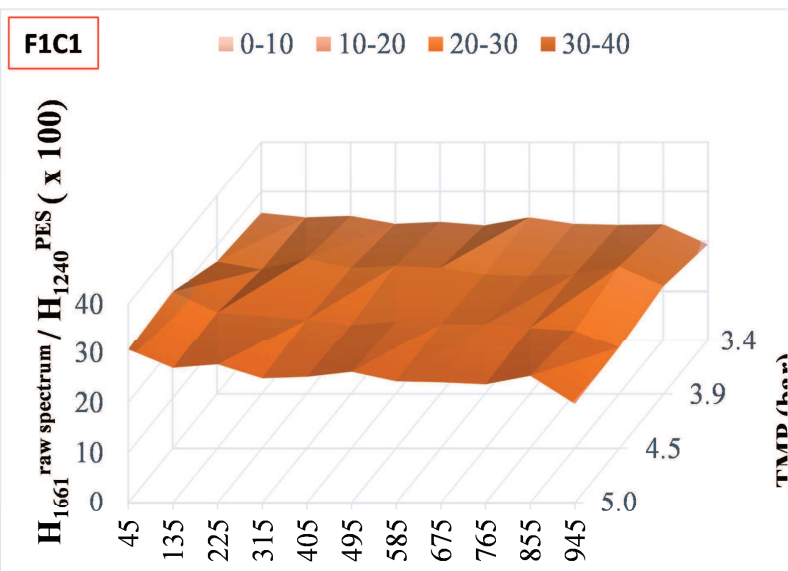

d (mm)

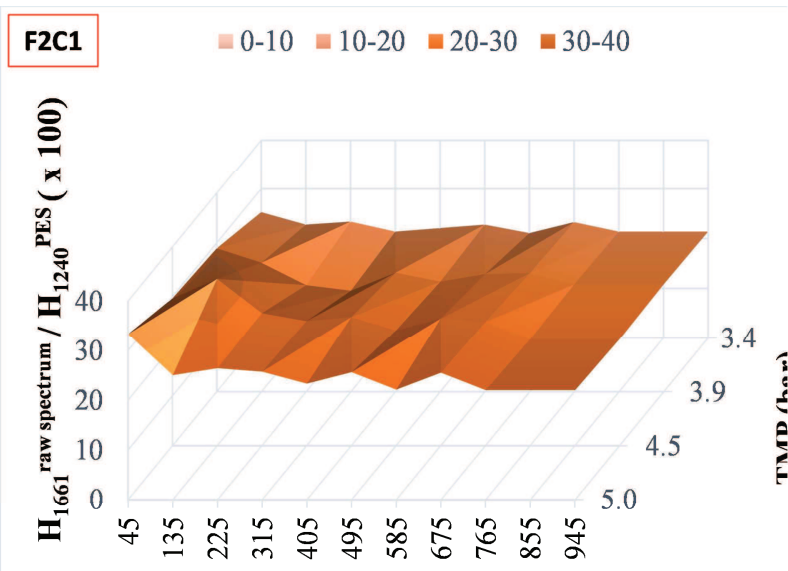

d (mm)

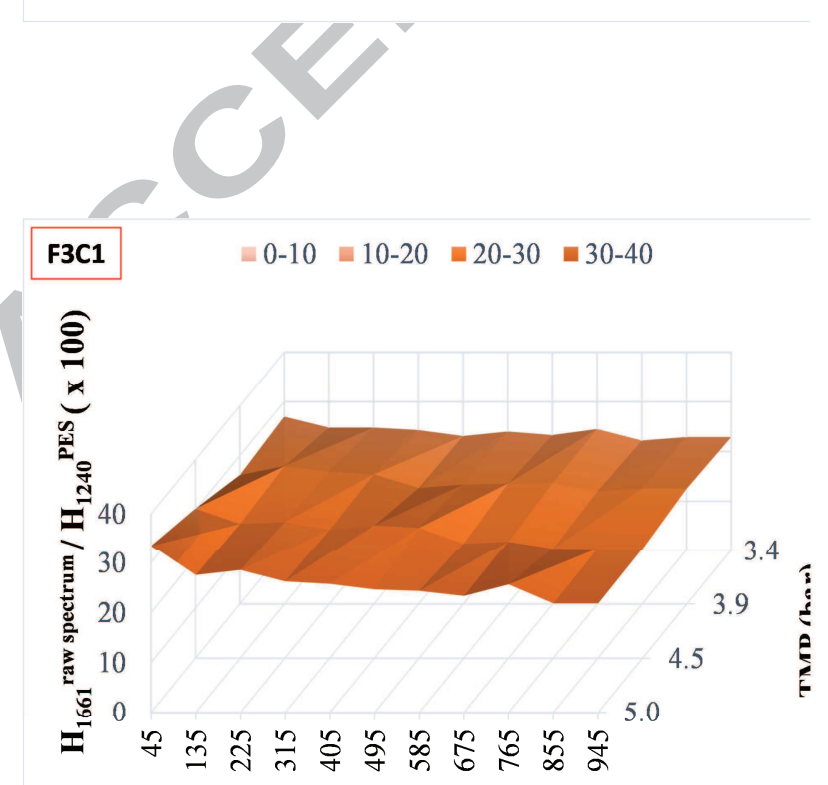

d (mm)

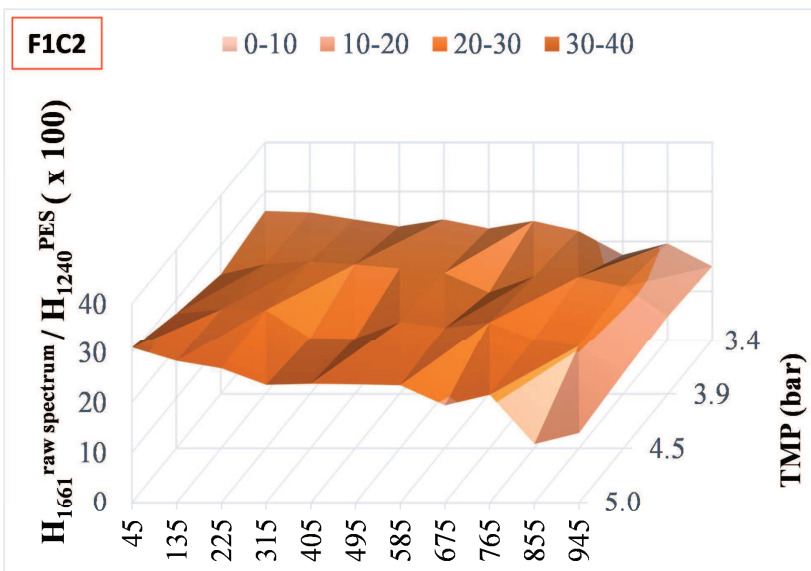

d (mm)

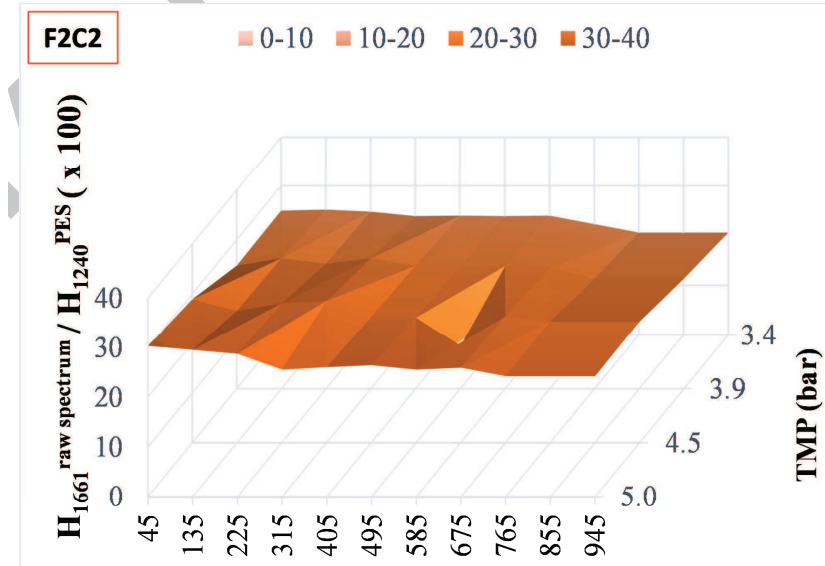

d (mm)
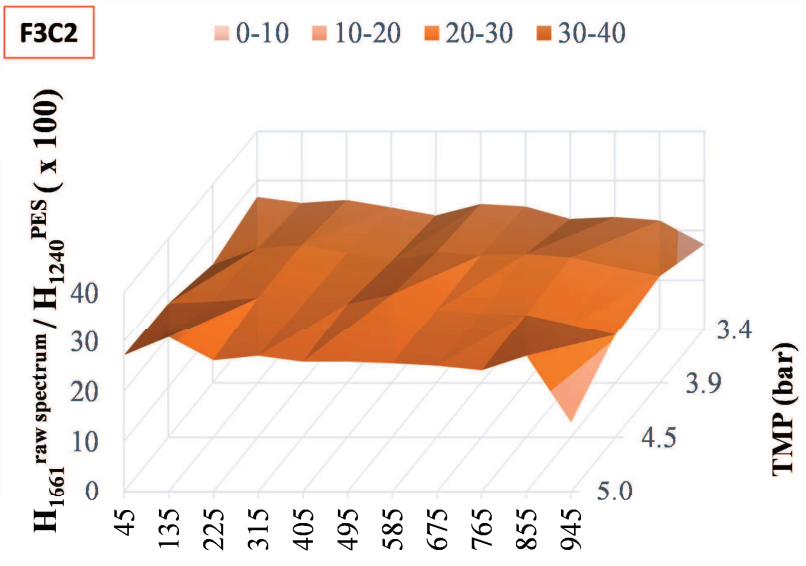

d (mm) 

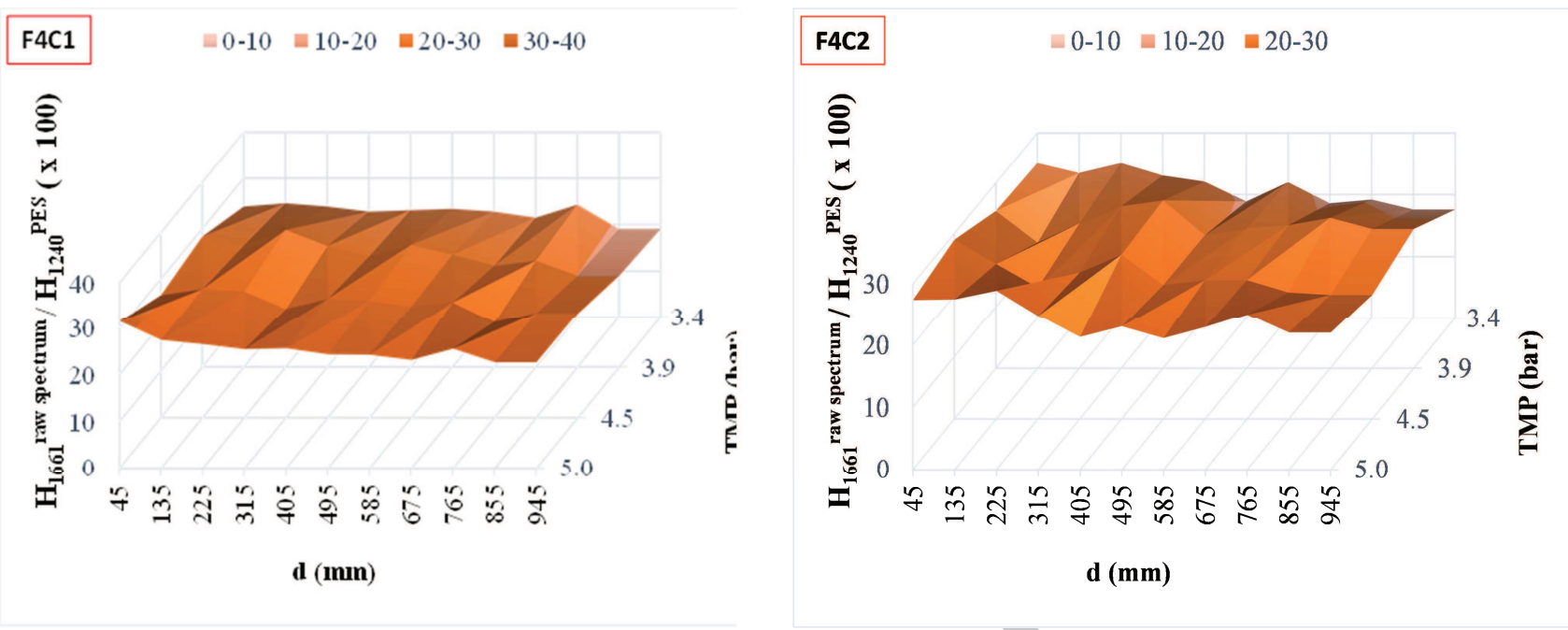

Figure 11 Mapping of $\mathrm{H}_{1661}$ raw spectrum $/ \mathrm{H}_{1240}$ PES obtained from FTIR-ATR according to the location in the spiral membrane. The local TMP is calculated from the assumption of a linear pressure drop decrease. The membrane labels are defined on Figure 8. TMP decreases from the inlet to the outlet of the spiral membrane. $d$ is the distance from the permeate axis $(d=0)$ for a membrane sheet. 


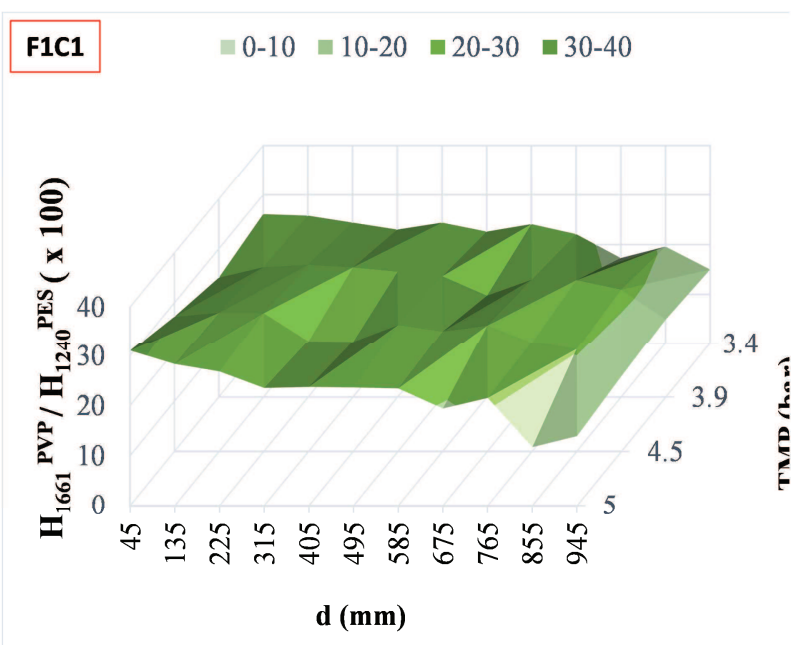

F1C2 $\square 0-10 \square 10-20 \square 20-30 \square 30-40$

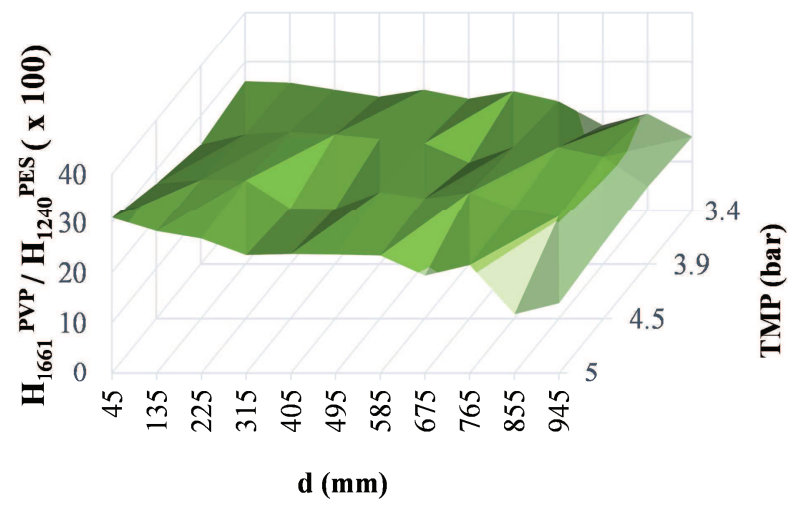

F2C1 $\square 0-10=10-20 \backsim 20-30 \backsim 30-40$

F2C2

$\square 0-10=10-20=20-30 \quad \square 30-40$

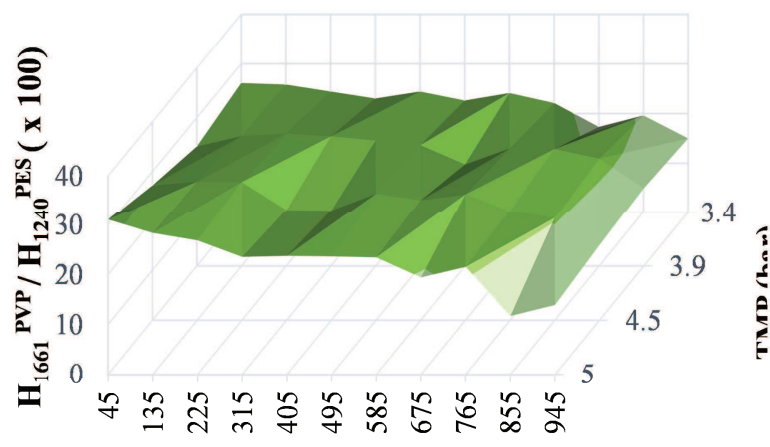

d (mm)

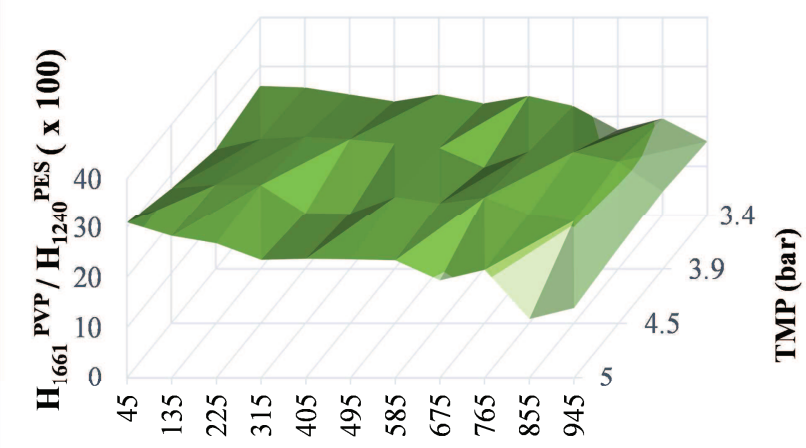

d (mm)

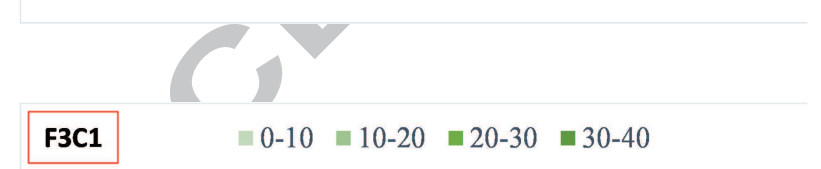

F3C2 $\square 0-10 \square 10-20=20-30 \quad \square 30-40$

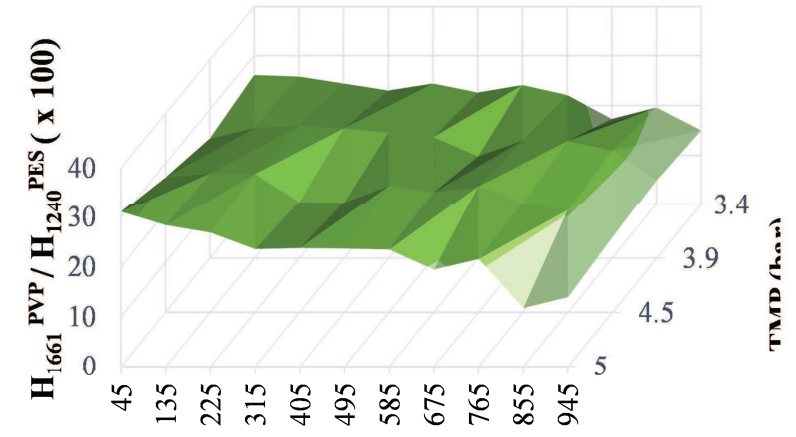

d (mm)

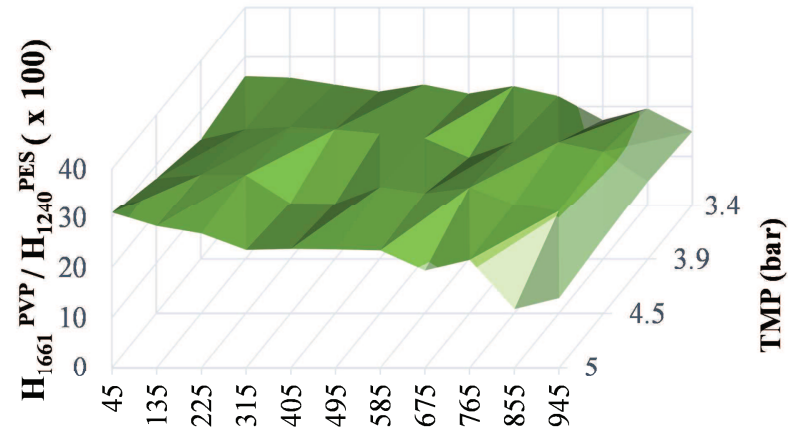

d (mm) 

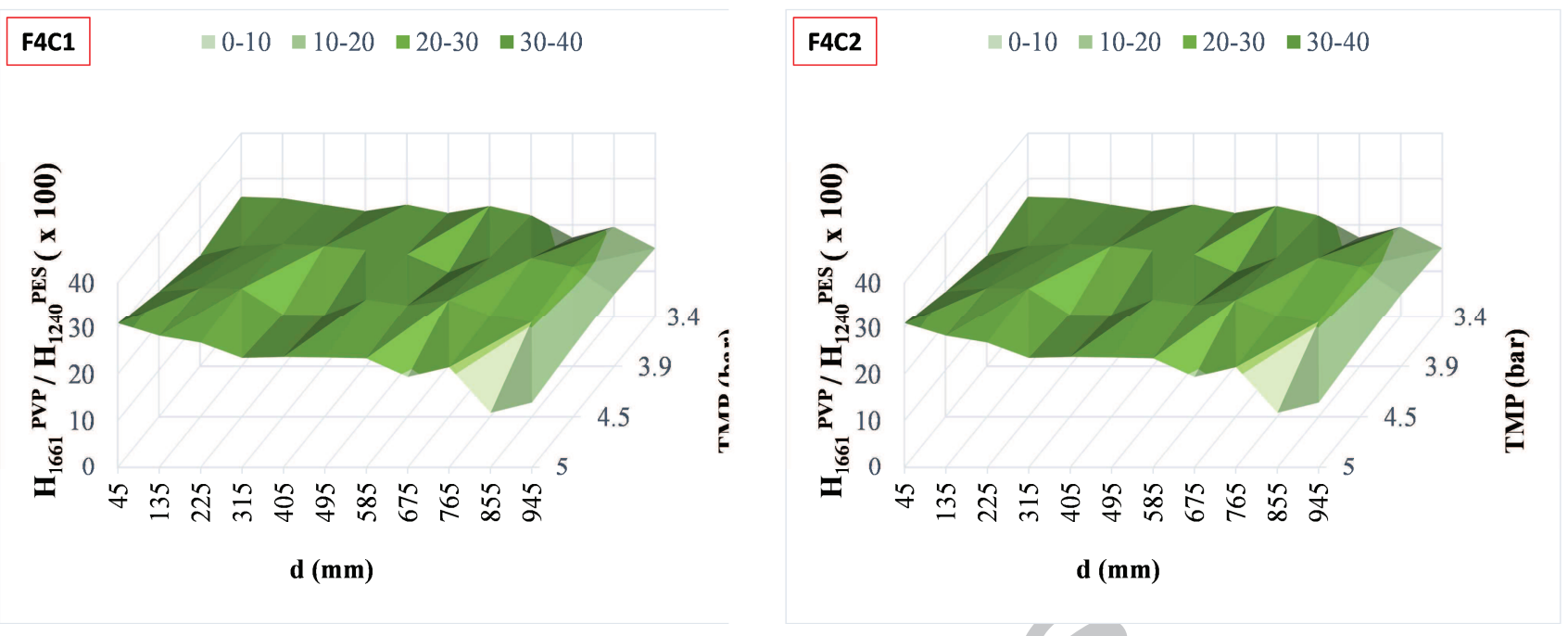

Figure 12. Mapping of $\mathrm{H}_{1661}{ }^{\mathrm{PVP}} / \mathrm{H}_{1240}$ PES obtained from equation 3 according to the location in the spiral membrane. The local TMP is calculated from the assumption of a linear pressure drop decrease. The membrane labels are defined on Figure 8. TMP decreases from the inlet to the outlet of the spiral membrane. $d$ is the distance from the permeate axis $(d=0)$ for a membrane sheet 


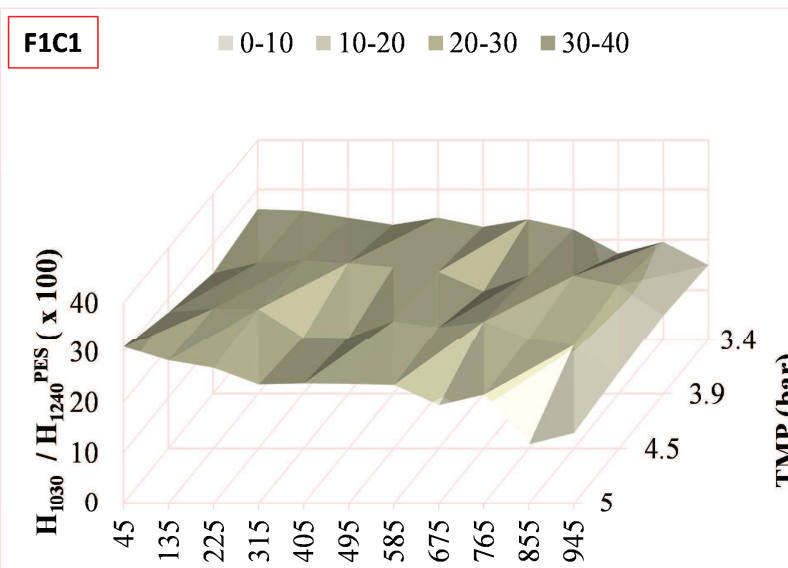

d (mm)

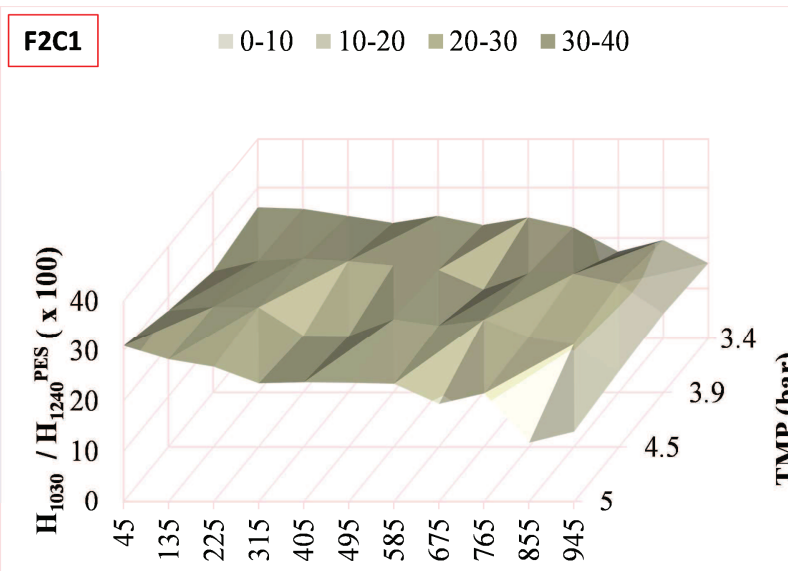

d (mm)

F3C1

$\square 0-10 \square 10-20 \square 20-30 \square 30-40$

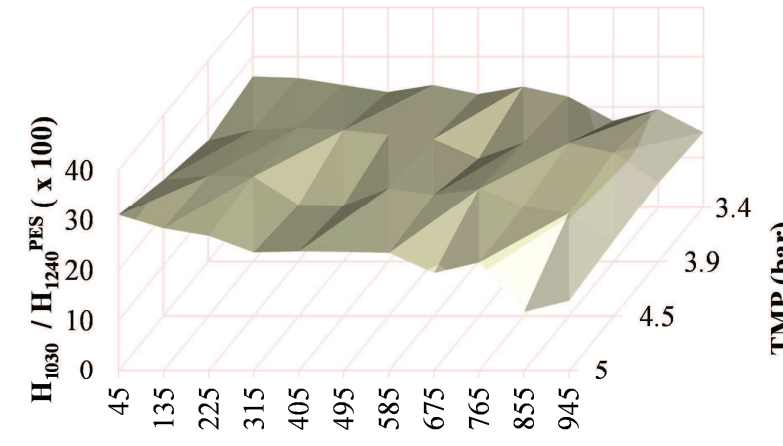

d (mm)

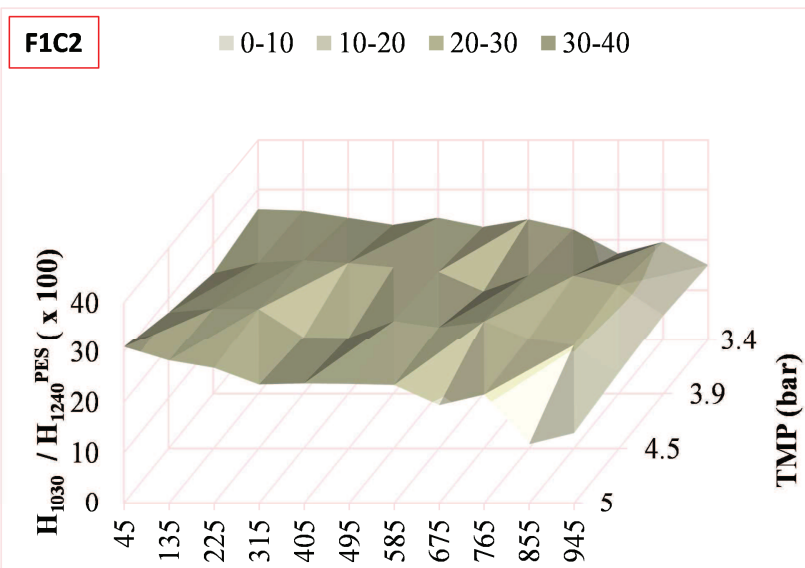

d (mm)

F2C2 $\quad \square 0-10 \square 10-20 \backsim 20-30 \square 30-40$

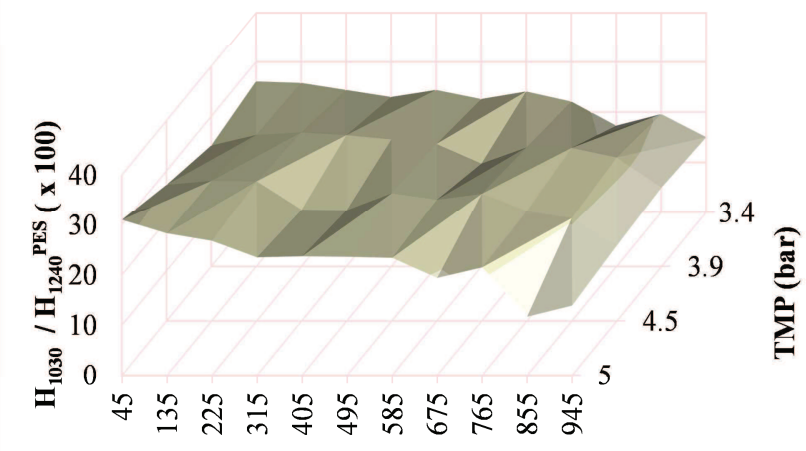

d (mm)

F3C2 $\square 0-10 \square 10-20 \backsim 20-30 \square 30-40$

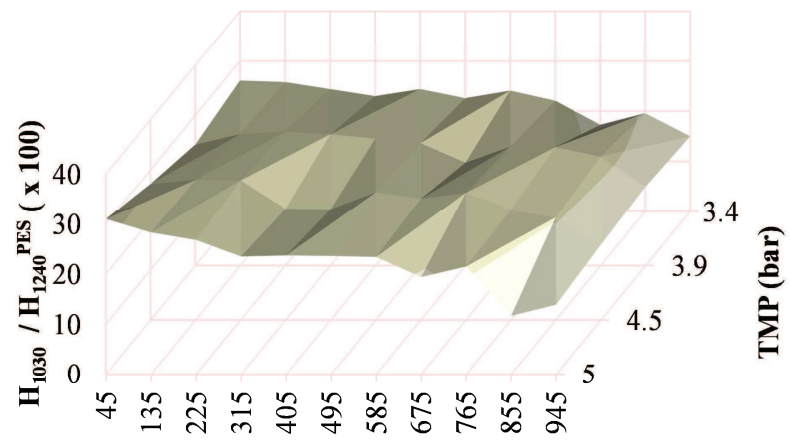

d (mm) 


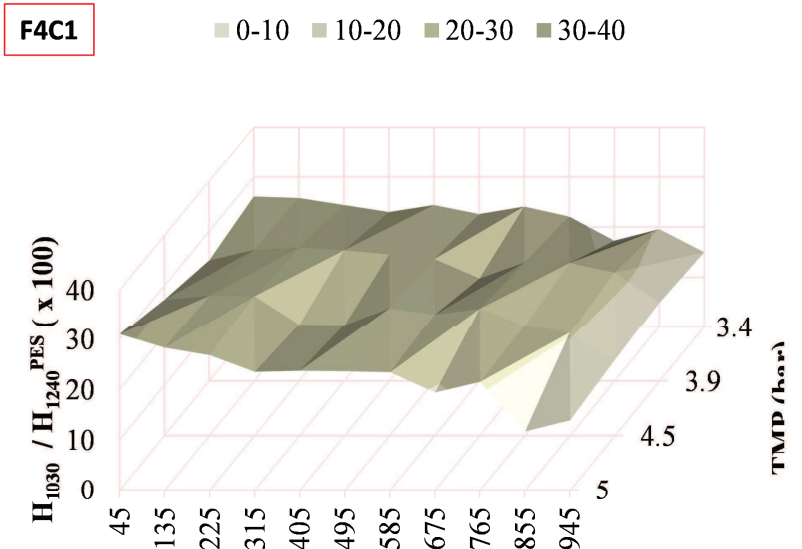

d (mm)
F4C2 $\quad \square 0-10 \backsim 10-20 \backsim 20-30 \backsim 30-40$

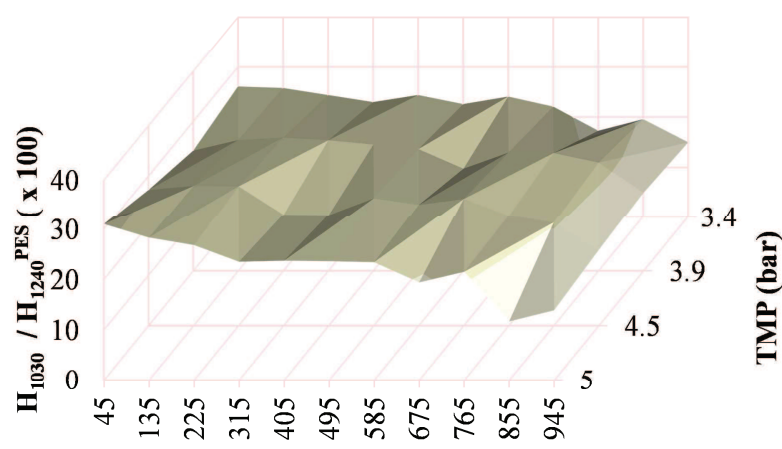

d (mm)

Figure 13. Mapping of $\mathrm{H}_{1030} / \mathrm{H}_{1240}{ }^{\text {PES }}$ according to the location in the spiral membrane. The local TMP is calculated from the assumption of a linear pressure drop decrease. The membrane labels are defined on Figure 8. TMP decreases from the inlet to the outlet of the spiral membrane. $d$ is the distance from the permeate axis $(d=0)$ for a membrane sheet 
Highlights

- evidencing PES/PVP membrane degradation by FTIR despites presence of protein fouling

- - methodology of treatment of FTIR spectra to reveal membrane degradation due to $\mathrm{NaOCl}$

$-$

- application to mapping of PVP degradation due to $\mathrm{NaOCl}$ in a spiral membrane

- $\quad$ - application to mapping of PES degradation due to $\mathrm{NaOCl}$ in a spiral membrane 